\title{
Evaluation of the IRAD Flexible-Probe Sonic Extensometer : :
}

\author{
H. D. Glenn \\ W. C. Patrick \\ N. L. Rector \\ L. S. Butler
}

Manuscript date: November 1984

\section{LAWRENCE LIVERMORE LABORATORY} University of California • Livermore, California • 94550 


\section{Contents}

Abstract $\ldots \ldots \ldots \ldots \ldots \ldots \ldots \ldots \ldots \ldots \ldots \ldots \ldots \ldots \ldots \ldots \ldots \ldots \ldots \ldots \ldots \ldots \ldots \ldots \ldots \ldots \ldots \ldots, 1$

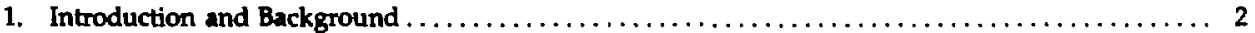

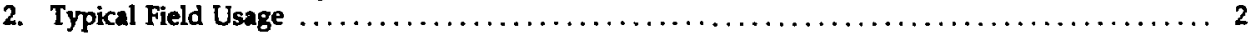

3. Experimental Results $\ldots \ldots \ldots \ldots \ldots \ldots \ldots \ldots \ldots \ldots \ldots \ldots \ldots \ldots \ldots \ldots \ldots \ldots \ldots \ldots, 4$

3.1. Evaluation of the Electronic Circuitry in the MB-7D Readout Box $\ldots \ldots \ldots \ldots \ldots \ldots \ldots 4$

3.1.1. Crystal Oscillator Stability $\ldots \ldots \ldots \ldots \ldots \ldots \ldots \ldots \ldots \ldots \ldots \ldots \ldots \ldots, \ldots$

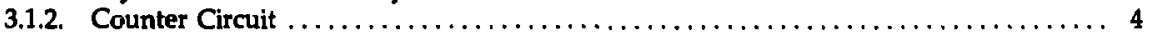

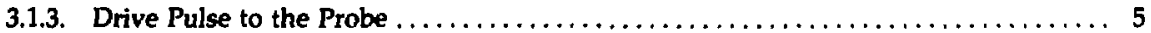

3.1.4. Return-Pulse Amplifier and Schmitt Trigger $\ldots \ldots \ldots \ldots \ldots \ldots \ldots \ldots \ldots \ldots \ldots \ldots, 6$

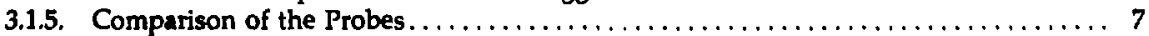

3.2. Measurement Accuracy at Ambient Temperatures $\ldots \ldots \ldots \ldots \ldots \ldots \ldots \ldots \ldots \ldots \ldots \ldots 7$

3.2.1. Distance Correction Factors $\ldots \ldots \ldots \ldots \ldots \ldots \ldots \ldots \ldots \ldots \ldots \ldots \ldots \ldots \ldots, \ldots$

3.2.2. Displacement Measurements $\ldots \ldots \ldots \ldots \ldots \ldots \ldots \ldots \ldots \ldots \ldots \ldots \ldots \ldots \ldots \ldots \ldots, 9$

3.3. Sensitivity to High-Explosives Shocks $\ldots \ldots \ldots \ldots \ldots \ldots \ldots \ldots \ldots \ldots \ldots \ldots \ldots \ldots \ldots \ldots$

3.3.1. Experimental Procedure for the High-Explosives Tests $\ldots \ldots \ldots \ldots \ldots \ldots \ldots \ldots \ldots, 18$

3.3.2. Experimental Results of High-Explosives Tests $\ldots \ldots \ldots \ldots \ldots \ldots \ldots \ldots \ldots \ldots \ldots, 20$

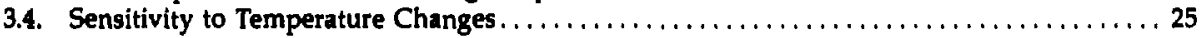

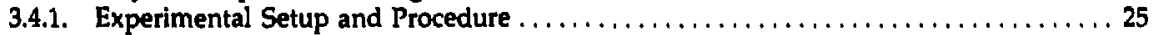

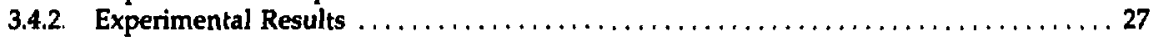

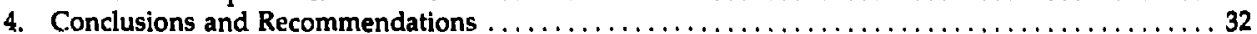

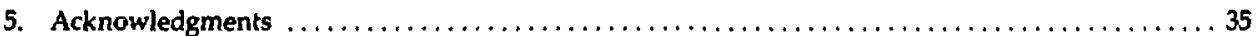

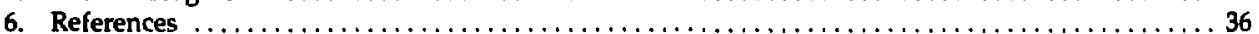




\section{Evaluation of the IRAD \\ Flexible-Probe Sonic \\ Extensometer}

\section{Abstract}

The evaluation of the IRAD flexible-probe sonic extensometer consisted of:

- A performance analysis of the MB-7D readout electronic circuit.

- An accuracy check of the system for both distances and small displacements.

- Measurements of sensitivity to strong shocks.

- Measurements of sensitivity to temperature changes.

The electronic-circuit analysis indicated an accuracy of $\pm 0.001 \mathrm{in} .(0.025 \mathrm{~mm})$ that is limited primarily by the counter circuit. Other components of the readout circuit (e.g." crystal oscillator, pulse generator, and amplifiers) gave consistently stable and reliable responses. A test bed was designed and fabricated to check the ability of the sonic probe to measure accurately small displacements of a magnetic anchor and the distance between two magnetic anchors. Two sonic probes used in these tests indicated reading accuracies of \pm 0.002 and \pm 0.003 in. $(0.051$ and $0.076 \mathrm{~mm})$ for a series of small displacements over the range of \pm 0.001 to \pm 0.050 in. (0.025 to $1.27 \mathrm{~mm})$. Both probes indicated that the readings for different distances between two magnetic anchors consistently were low by $2 \%$.

Sensitivity of the sonic-probe system to strong shock waves in granite was investigated with a series of high-explosive tests in the Climax tunnel complex at the Nevada Test Site. Five magnetic anchors were located in a borehole, and three $50,000 \mathrm{~g}$ accelerometers were installed in separate boreholes nearby. Peak radial accelerations of from $2,100 \mathrm{~g}$ up to about $32,000 \mathrm{~g}$ were measured after the detonation of individual line charges at varying distances. Sonic-probe readings of the uistance between magnetic anchors, taken before and after each line-charge detonation, had differences that generally fell within the inherent accuracy $( \pm 0.002 \mathrm{in}$. $[0.051 \mathrm{~mm}])$ for the sonic extensometer that was used.

A temperature bath, which incorporated the test bed used in the displacementaccuracy tests, was designed and built to check the sensitivity of the sonic probe to temperature variations. Sonic-probe readings exhibited a definite sensitivity to temperature changes over the range of 20 to $50^{\circ} \mathrm{C}$ for the four segments of the probe that were monitored. Although the linearly weighted average for the correction factor of $4.05 \times 10^{-6}$ in./in. ${ }^{\circ} \mathrm{C}$ was obtained for those four segments and was well within the limits of 3.6 to $5.4 \times 10^{-6}$ in./in..$^{\circ} \mathrm{C}$ cited by the manufacturer, the correction factor for the last two segments exceeded those limits. Recommendations are made for increasing the accuracy and performance of the IRAD sonic extensometer and other studies are suggested to supplement the present report. 


\section{Introduction and Background}

The Canadian government is studying the feasibility of disposing of high-level nuclear waste in underground vaults situatad deep in granitic formations of the Canadian shield. For this purpose, Atomic Energy of Canada, Ltd., (AECL) is developing the Underground Research Laboratory (URL) to examine technical problems related to nuclear waste disposal in granite intrusions. The experience gained by the Lawrence Livermore National Laboratory (LLNL) in conducting the Spent Fuel Test-Climax (SFT-C) in a granite intrusion at the Nevada Test Site (NTS) was applicable to these investigations. To provide a mechanism for performing research of mutual benefit to the AECL and the U.S. crystalline rock programs, a U.S./Canadian Cooperative Agreement was formulated, and it is administered and funded by the U.S. Department of Energy's Office of Crystalline Repository Development (DOE-OCRD).

Initially, the SFT-C Project was planned as a 3- to 5-year test, ${ }^{1}$ and instrumentation was selected ${ }^{2}$ that was specified to be capable of surviving the test environment for that period of time. An extensive array of instruments was installed at the Climax site to provide an experimental basis for checking the computer-based models used to simulate inie experimental results numerically. ${ }^{3,4}$ A significant fraction of the instruments initially installed falled. Failure was attributed primarily to the hostile environment to which the instruments were subjected.

The need to identify or develop instruments to provide long-term monitoring of geotechnical parameters in nuclear waste repositories has been reviewed recently. ${ }^{6}$ One of the more promising instruments, one that could potentially satisfy many of the requirements cited, ${ }^{6}$ is the IRAD flexible-probe sonic extensometer. The principal advantage of this system is that it is portable, and the sonic probe is inserted in a borehole only at the time readings are made. Consequently, the IRAD sonic extensometer, unlike instruments used previously, can be stored in a benign environment between measurements and not be continually exposed to a hostile environment. This system does use permanently emplaced magnetic anchors, but they are sturdy and should withstand the environment in the borehole. In addition, the anchors are not spring-loaded in the direction of the borehole axis (as are other types of extensometers) and, therefore, are not as likely to be affected by shock loading from blasting for excavation nor by tension-induced creep.

This report supplements an earlier study ${ }^{8}$ that discussed the suitability of using the IRAD sonic extensometer in the URL. In particular, it investigates the first four recommendations made in that report concerning:

- Basic accuracy of the instrument.

- Temperature sensitivity.

- Shock sensitivity.

- Evaluation of the electronic circuit.

\section{Typical Field Usage}

In this section we shall describe the probe's normal emplacement and operation in a typical field experiment. Initially, up to ten magnetic anchors are installed at preselected positions in a borehole. A hollow, aluminum guide tube is then inserted through the magnetic anchors. The guide tube is screwed to an anchor located at the collar of the borehole. The flexible sonic probe can then be inserted into the guide tube and secured in place with a J-slot located in the collar anchor. The J-slot insures that the sonic probe is repositioned accurately each time it is inserted into the borehole. Finally, a cable from the head of the sonic probe is attached to the input of the MB-7D readout box, and the IRAD sonic extensometer is ready for use.

The MB-7D readout box evaluated in this study was configured to measure the distance or interval between two successive magnets located in the borehole. The choice of which specific interval is to be examined is determined by a ten-position selector switch mounted on the top of the MB-7D readout box.

Once the interval of interest is selected, a toggle switch on the readout box is depressed and a pulse generator sends a series of 25 electronic pulses down a wire in the sonic probe at about one second intervals. Each pulse is approximately rectangular in shape, having a $3-\mathrm{V}$ amplitude and $1-\mu \mathrm{s}$ width. The magnetic field associated with the pulse current interacts with the magnetic field of the permanent magnets at each of the anchor locations. The interaction of these two magnetic fields induces a magnetic 
stricture in the nickel-cadmium alloy tube in the sonic probe. The magnetic stricture generates a streas pulse at each anchor that propagates with the characteristic sonic velocity of the probe in both directions away from each of the magnetic anchors. The stress pulse arriving at the probe head is detected by a transducer and converted into an electric signal.

The electric signal is amplified in the probe head and sent to the MB-7D where it is amplified a second time (Fig. 1). The signal activates a Schmilt-trigger (flip-flop) circuit and starts the counter circuits for a specific magnetic anchor that was determined by the position of the selector switch. The stress pulse from the next magnetic anchor located farther down the borehole is amplified. This signal again activates the Schmitt trigger and stops the counter circuit. The oscillator frequency was chosen by the manufacturer to be $110.13 \mathrm{MHz}$ because the period of one cycle corresponds to the time necessary for the stress pulse to propagate $0.001 \mathrm{in}$. $(0.025 \mathrm{~mm})$ with its characteristic sonic velocity, $\approx 9177.5 \mathrm{ft} / \mathrm{s}(2797.3 \mathrm{~m} / \mathrm{s})$, in the magnetic-strictive probe. The liquid-crystal display on the MB-7D box indicates the oscillator count and is equivalent to the distance in inches between two successive magnetic anchors with the resolution of 0.001 in. $(0.025 \mathrm{~mm})$. In practice, each recorded reading for the interval between two magnetic anchors consists of a mental average of 25 different readings that were spaced about one second apart following depression of the toggle or pulse switch. Generally, each of the 25 readings only varied in the final digit ( 0.001 in. [0.025 mm]) position since all 25 readings are fo: the same distance interval. The accuracy of this measurement is one aspect of the evaluation of the IRAD sonic probe that we investigated.

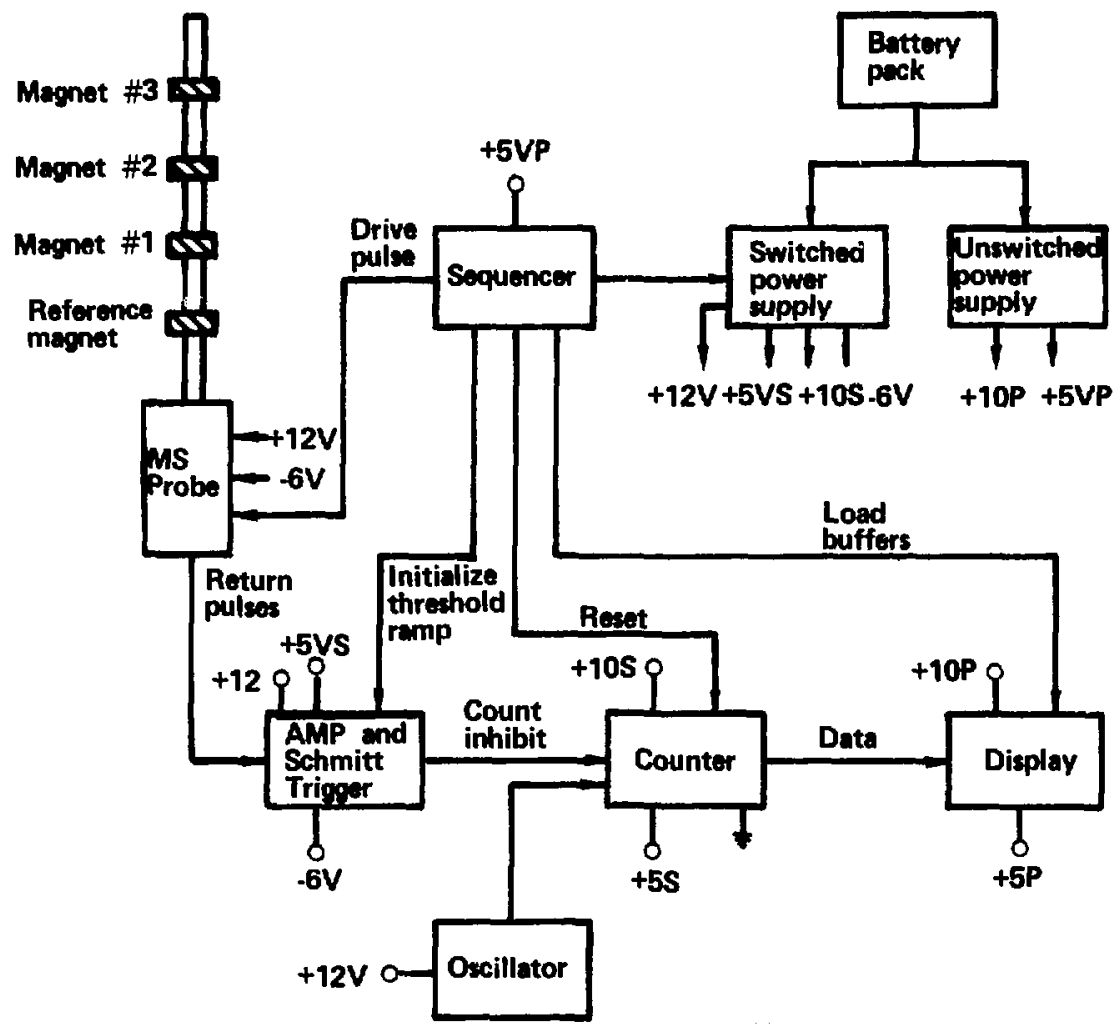

MSS readout block diagram

Figure 1. Block diagram of the magnetic-strictive sonic probe and the MB-7D readout box. (See Ref. 9 for further explanation.) 


\section{Experimental Results}

The IRAD sonic extensometer was subjected to a variety of experimental tests to examine different aspects and sensitivities of the systems. The results from those experimental tests are described in the following four subsections. We first present a description of the electronic circuit analysis. We isolated the portion of the reading variations due to the electronic circuits for the MB-7D readout from that due to the sonic probe. This analysis provides a basic understanding of how the system functions and suggests posaible modification for improved performance and accuracy. Then we discuss our investigations of the accuracy of the MB-7D readout when measuring the distance between two magnetic anchors and to small changes in the position of magnetic anchor. The third subsection concerns the anchoring system's response to shock interaction generated by nearby chemical explosives. Finally, the sensitivity of the sonic probe is examined for temperature changes in the range of 20 to $50^{\circ} \mathrm{C}$.

Most of the results reported here were conducted with a sonic probe (S/N 1001) that had been carefully selected at IRAD for our use. ${ }^{10}$ On june 21, 1983, we received a second sonic probe (S/N A1012RP) that was out of stock and not screened as was the earlier one. For the sake of simplicity, we have designated the two probes the "selected" and "stock" probes, respectively. While both probes were used in the electronic circuit analysis and accuracy tests, only the selected probe was used in the high-explosive and temperature studies. This cholce was based on the better accuracy of the selected probe. It was not considered operationally feasible or necessary to field both probes in the last two studies cited.

\subsection{Evalsation of the Electronic Circuitry in the MB-7D Readout Box}

The basic operation and functions of various components of the electronic circuits for the IRAD sonicextensometer systems were described earlier. In this subsection we shall examine in detail only the electronic circuit in the MB-7D readout box. We made an attempt to examine the preamplifier circuit locsted in the head assembly of the probe, but return signals from the magnetic anchors were too weak for us to measure accurately without significantly altering waveforms. Consequently, the preamplifier in the probe head of the sonic-extensometer system was not analyzed. The components of the MB-7D readout that were examined and the order in which they will be reported are: 1) the crystal oscillator, 2) the counter circuit, 3) the probe drive generator, and 4) the retum-pulse amplifier and Schmitt trigger (a threshold detection circuit). We also compare the return signal from the two probes.

\subsubsection{Cryatal Oscillator Stability}

The frequency of $110.13 \mathrm{MHz}$ was chosen for the oscillator since, at this frequency, the period of one cycle corresponds to the time that the stress pulse takes to travel $0.001 \mathrm{in}$. $(0.0254 \mathrm{mim})$ along the sonic probe. Thus, the display on the MB-7D box corresponds to the oscillator count and is also equivalent to the distance in inches between two magnetic anchors. The resolutions for these distance readings would theoretically be $0.001 \mathrm{in}$. $(0.0254 \mathrm{~mm})$. Since the crystal oscillator is so fundamental to the distance measurements, a check of the crystal's stability was made. The crystal oscillator in the MB-7D box was rewired so that the crystal was in a free running mode to ensure an accurate reading on the external frequency counter. Frequency readings were taken hourly during the day for a three-day period. Over this period the frequency of the oscillator was $110.12994 \pm 0.001 \mathrm{MHz}$. An error of this magnitude normally would not show up on the MB-7D readout because it has a six-digit resolution. Consequently, the crystal oscillator is capable of achieving an accuracy of better than $0.001 \mathrm{in} .(0.0254 \mathrm{~mm})$.

\subsubsection{Counter Circuit}

An important part of each distance reading with the MB-7D readout is the electronic circuit used to count the number of cycles between two return pulses. To evaluate the accuracy of the counter circuit, the sonic-probe cable was disconnected, and an external time synthesizer was used to simulate the return signals from the sonic probe. Initially, a time interval of $393.70078 \mu$ s was synthesized to simulate a distance of $\mathbf{4 3 . 3 5 9} \mathrm{in}$. $(1.1013 \mathrm{~m})$, which corresponds approximately to the interval between the first two magnetic anchors used in the accuracy tests we describe in the following subsection. For this time interval, the MB-7D readings ranged from 43.358 to $43.360 \mathrm{in}$., with an average reading of $43.359 \mathrm{in}$. $(1.1012 \mathrm{~m})$. Then the time interval was increased by increments of $0.00908 \mu \mathrm{s}$ to simulate the displacement of $0.001 \mathrm{in}$. (0.0254 mm). 
This pattern of time increment changes was continued until the correaponding diaplacement of 0.01 in. $(0.254 \mathrm{~mm})$ was attained. Then the time increments were increased to correspond to additional displacement of 0.005 and $0.01 \mathrm{in} .(0.127$ and $0.254 \mathrm{~mm})$. The time increment format followed the format used in the displacement measurements of the next subsection. For example, with the time synthesizer set at $393.79158 \mu \mathrm{s}$, an increase of $0.0908 \mu \mathrm{s}$, the MB-7D displays had readings of 43.369 and 43.370 in., with an average reading of $43.369 \mathrm{in}$. $(1.1016 \mathrm{~m})$. This corresponds to displacement of $+0.01 \mathrm{in}$. $(0.254 \mathrm{~mm})$ with respect to the original setting and agrees with total change in the time increments. In addition to increasing the time interval to simulate positive displacements, a comparable set of readings was taken in which the time interval was decreased to simulate negative displacements. In summary, the time synthesizer was used to simulate displacements of $0.001 \mathrm{in}$. $(0.025 \mathrm{~mm})$ from 0.0 to $\pm 0.01 \mathrm{in}$. $(0.0$ to $0.254 \mathrm{~mm})$, 0.005 in. $(0.127 \mathrm{~mm})$ from \pm 0.01 to \pm 0.02 in. $(0.254$ to $0.508 \mathrm{~mm})$, and $0.01 \mathrm{in}$. $(0.254 \mathrm{~mm})$ from \pm 0.02 to \pm 0.05 in. $(0.508$ to $1.270 \mathrm{~mm})$. The readings averaged by the $\mathrm{MB}-7 \mathrm{D}$ very accurately tracked the timesynthesized displacements. However, each averaged reading had a range of up to $\pm 0.001 \mathrm{in}$. $(0.0254 \mathrm{~mm})$. Actually, a plus- or minus-one count $( \pm 0.001 \mathrm{in}$. $[0.0254 \mathrm{~mm}])$ variation is inherent in binary-codeddecimal (BCD) counters. An improved, high-frequency counter circuitry would reduce this error but would require a corresponding increase in the crystal frequency.

\subsubsection{Drive Pulse to the Probe}

Following depression of the toggle switch on the MB-7D box, a series of drive pulses are generated that propagate along the sonic probe. We examined how reproducible the pulses are and how sensitive the MB-7D readings are to variations in the pulse shape. These features and other aspects of the drive pulse sent to the sonic probe are discussed below.

To determine the repeatability of the pulse shape, a series of ten oscilloscope traces were recorded on film. All ten traces for the drive pulse were in excellent agreement, not only in magnitude but in every particular of the waveform. Each drive pulse had an initial rise time of $4 \mathrm{~ns}$ to the $2 \mathrm{~V} \mathrm{~V}$ level where it remained for $30 \mathrm{~ns}$. The pulse then had a rise time of 7 to $8 \mathrm{~ns}$ to a level of $3 \mathrm{~V}$, where it stayed for the remainder of the $1-\mu \mathrm{s}$ pulse width. The $2-\mathrm{V}$ step is a minor perturbation to the pulse shape. The $30-\mathrm{ns}$ step at $2 \mathrm{~V}$ is attributed to an impedance mismatch between the 43-ohm cable that connects the MB-7D box to the probe and the 93-ohm input of the probe head.

An external pulse generator was substituted for the probe drive-pulse generator in the MB-7D to simulate the 4-ns rise and fall times and the 1- $\mu$ s-width drive pulse. The amplitude of the drive pulse was slowly decreased until at $1.4 \mathrm{~V}$ the MB-7D failed to give a reading for spacing between anchors of 43.264 in. $(1.1 \mathrm{~m})$. Therefore, any drive pulse with an amplitude equal to or less than $1.4 \mathrm{~V}$ will not be sufficient to generate a return signal. A pulse height just slightly in excess of the 1.4-V threshold indicated no degradation of the return signal or change in the MB- $7 D$ reading. To determine whether the threshold was aufected by spacing between two magnetic anchors, both probes were checked at 1 and $18 \mathrm{ft}(0.3$ and $5.5 \mathrm{~m}$ ). The amplitude from the external pulse generator was slowly decreased until there was no reading on the MB-7D. For both probes, the lower threshold necessary for the drive pulse to generate a return signal was determined to be about $1.4 \mathrm{~V}$ for both the $1-$ and $18-\mathrm{ft}(0.3-$ and $5.5-\mathrm{m})$ intervals between two magnetic anchors. Despite a constant threshold voltage of $1.4 \mathrm{~V}$, the return signal in the sonic probe does attenuate with distance. From the time the drive pulse is generated, the amplifier increases the amount of amplification linearly with time for the return signal. Consequently, return signals from magnetic anchors located further from the probe head undergo a proportionally greater amplification. This fact may clarify the constant $1.4-\mathrm{V}$ threshold for the amplitude of the drive pulse to generate a return signal and obtain a MB-7D reading irrespective of the distance between two anchors.

To investigate further the sensitivity of the return signal and MB-7D readings, we reconnected the probe to the MB-7D. Then two magnetic anchors were set $43.263 \mathrm{in}$. (1.1 m) apart, and a reading of the signal traveling between them was recorded. Again, the external pulse generator was connected to the probe and sensitivity of the return signals and MB-7Ds readings examined as a function of changes in drive pulse. Results for the MB-7D readings to changes in the drive pulse shape are summarized in Table 1. With the exception of a small increase in the range of the readings about the average value, the test results suggest a high degree of insensitivity to wide variations in the shape of the drive pulse. Records of the oscilloscope traces for each entry in the table did not reveal any discernible change in the waveforms for the return signals. 
Table 1 . Seadivity of MB-7D readinge to variations in the dive pelise to the probe.

\begin{tabular}{|c|c|c|c|c|}
\hline $\begin{array}{l}\text { Drive- } \\
\text { palie } \\
\text { enurce }\end{array}$ & $\begin{array}{l}\text { Rhe and } \\
\text { fall times } \\
\text { (nos) }\end{array}$ & $\begin{array}{l}\text { Pulve } \\
\text { width } \\
\text { (ke) }\end{array}$ & $\begin{array}{l}\text { Pulse } \\
\text { helght } \\
\text { (V) }\end{array}$ & $\begin{array}{l}\text { MB-7D } \\
\text { reading } \\
\text { (in.) }\end{array}$ \\
\hline ME-TD & 4 & 1 & 3 & $43.263 \pm 0.003$ \\
\hline External & 4 & 1 & $1.4+$ & $13.263 \pm 0.003$ \\
\hline External & $\mathbf{5}$ & 1 & $13^{\mathbf{a}}$ & $43.263 \pm 0.003$ \\
\hline External & 100 & 1 & 3 & $43.264 \pm 0.004$ \\
\hline Exteraal & 1000 & $\mathbf{5}$ & 3 & $43.264 \pm 0.004$ \\
\hline
\end{tabular}

Volkage limit of the external generator.

\subsubsection{Return-Pulse Amplifier and Schmitt Trigger}

The magnetic fleld associated with the current flow in the drive pulse interacts with the permanent magnetic field at each anchor location. This interaction produces the magnetic stricture that distorts the nlckel-cadmium tube and produces a stress wave that propagates along the sonic probe in both directions. At the head of the probe, the stress waves are detected by a torsional transducer (Villari effect) and converted into an electrical signal. ${ }^{7}$ A typical return signal following amplification in the probe head is illustrated in Fig. 2. When the signal enters the MB-7D readout, it is further amplified before it activates the Schmitt-trigger circuit. Output from the Schmitt-trigger circuit serves as input to the counter circuit to start or stop the counter that produces the distance reading on the MB-7D display. We studied the sensitivity of the Schmitt-trigger circuit to varying input, and in the following discussion we shall present our results.

To check the threshold voltage required for activating the Schmitt-trigger circuit, an external pulse generator was connected to the input amplifier of the MB-7D readout. The output of the Schmitt trigger was monitored with an oscilloscope to determine what input voltage is needed to activate the Schmitt trigger and provide an output. Table 2 summarizes the results of this test. The tabulated results indicate that an input voltage of at least $190 \mathrm{mV}$ from the probe head into the input amplifier of the MB-7D is required to ensure an output from the Schmitt-trigger circuit. The Schmitt-trigger output operates at a level of $+5 \mathrm{~V}$ and drops to approximately zero volts when triggered.

The counter circuit is sensitive to just the leading edge of output from the Schmitt-trigger circuit. Figure 3 illustrates a typical (negative) leading edge of the pulse when the IRAD sonic probe is used in its normal operating mode. An external pulse generator was substituted for the probe and used as input to supply a retum signal to the amplifier of the MB-7D. The output of the external pulse generator was set at $400 \mathrm{mV}$ as the rise/fall times and the pulse widths were varied. For example, the first externally generated pulse had a rise time and a fall time of $100 \mathrm{~ns}$ and pulse width of $1 \mu \mathrm{s}$. Table 3 summarizes results obtained from this study. The pulse width for each externally generated pulse corresponds to full width at half maximum amplitude. As the tabulated results indicate, the rise time of the output pulse for the Schmitt trigger is insensitive to large changes in the rise/fall times and the width of the input pulse.

Table 2. Determination of the threahold voltage required to activate the Schmitt-trigger circuit.

\begin{tabular}{ccc}
\hline $\begin{array}{c}\text { Input } \\
\text { voltage } \\
\text { mV }\end{array}$ & $\begin{array}{c}\text { Number } \\
\text { of } \\
\text { inpute }\end{array}$ & $\begin{array}{c}\text { Number } \\
\text { of } \\
\text { outputs }\end{array}$ \\
\hline 175 & 10 & 0 \\
160 & 10 & 4 \\
105 & 10 & 6 \\
190 & 10 & 10 \\
195 & 10 & 10 \\
200 & 10 & 10 \\
\hline
\end{tabular}

Table 3. Variation of the rise/fall times and width of the input pulse to determine sensitivity to rise time for the Schmitt-trigger output.

\begin{tabular}{ccc}
\hline $\begin{array}{c}\text { Input } \\
\text { rive/fall } \\
\text { time (Ms) }\end{array}$ & $\begin{array}{c}\text { Input } \\
\text { width }(\mu s)\end{array}$ & $\begin{array}{c}\text { Rise time of } \\
\text { Schmitt output } \\
\text { pulse (no) }\end{array}$ \\
\hline Normal pulse & 25 & 10 \\
0.7 & 1 & 10 \\
0.5 & 1 & 10 \\
1 & 2 & 10 \\
5 & 10 & 10 \\
10 & 20 & 10 \\
\hline
\end{tabular}


Figure 2. Return lipal frem the celected conic probe using the ME-7D drive-pulse generator. The vertical ecale is $200 \mathrm{mV}$ per division, and the horizontal scale is 10 wo per divialon.
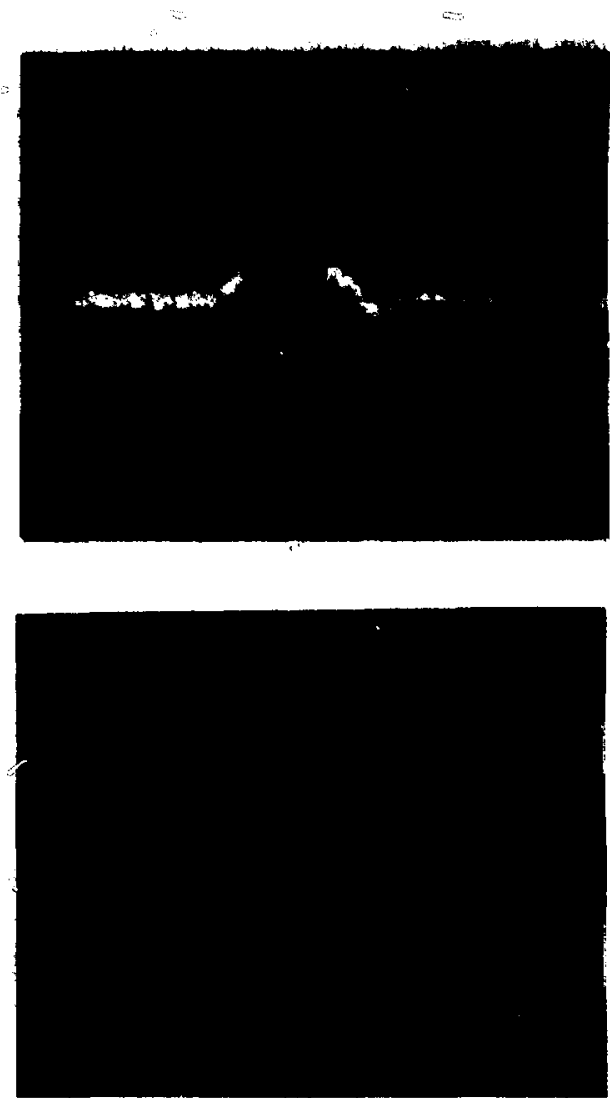

Figure 3. Leading (negative) edge of the pulse from the Schmitt trigger. The vertical scale is approximately $0.8 \mathrm{~V}$ per division, and the horizontal acale is $10 \mathrm{~ns}$ per dlvision.

\subsubsection{Comparicon of the Probes}

To compare the sensitivities of the selected probe and the stock probe, we located five magnetic anchors along an aluminum l-beam and generated a return signal from the anchors with the MB-7D box. We then examined the magnitude of the return signals for both probes. The five return signals from the selected probe exceeded $500 \mathrm{mV}$ and appeared to be nearly uniform in amplitude. The five return signals from the stock prote were less than $400 \mathrm{mV}$ and steadily decreased in amplitude until the last return signal only slightly exceeded the $190-\mathrm{mV}$ threshold needed to activate the Schmitt trigger. We suspect that greater attenuation occurs in the stock sonic probe than in the selected probe. This may be the result of greater variability in the material properties of the probes or surface irregularities on the stock probe. The ramp amplifier apparently could not compensate for the greater signal attenuation present in the stock probe.

\subsection{Measurement Accuracy at Ambient Temperatures}

Our basic objective in designing a test facility was to determine the accuracy of the IRAD sonic extensometer in measuring small displacements of the magnetic anchors. As described previously, a current pulse generates a magnetic field that interacts with the permanent magnetic field at each anchor. The interaction of the two magnetic fields induces a magneto-strictive pulse. The magnetic stricture generates a stress wave that propagates with its characteristic sonic velocity, $\approx 9177.5 \mathrm{ft} / \mathrm{s}(2797.3 \mathrm{~m} / \mathrm{s})$, 
fon the anonetic anchor location to the probe head, where it is converted by a tranaducer into an

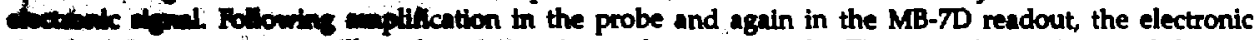

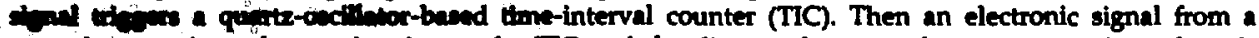

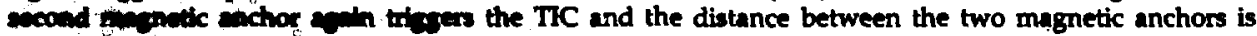
criculatid from a prescribed vahe for the sonic-wave velocity in the probe. The distance between the two magnetic anchors, to the neareat 0.001 in. $(0.025 \mathrm{~mm})$, appears on a liquid-crystal display on the MB-TD bow.

For a typical in situ application, the surrounding medium would normally be devoid of magnetic materials. To simulate this appect of the in situ environment, the bench fixture used in the laboratory tests was constructed of non-magnetic mpterials. For example, the cart used to support each magnetic anchor (Fig. 4) was fabricated from aluminum stock. Although the two micrometers (shown in Fig. 4) were obtained commercially, they were constructed of non-magnetic materials. In addition, the four springs used to support each magnetic anchor an' maintain positive contact with the micrometers and the four set screws for securing the position of ench cart were all made of brass. Finally, the track on which the carts were located was an aluminum (6061-T6) I-beam, $20 \mathrm{ft}(6.1 \mathrm{~m})$ long. The aluminum l-beam, collar anchor, and a total of five carts with magnetic anchors were assembled in the laboratory on a wooden bench well away from any metallic surfaces or instruments that might influence or induce perturbations in the readings. By maintaining strict control on the surroundings, we strove to eliminate extraneous effects that might influence the measurements.

An example of extraneous effects that could alter results of the measurements is changes in temperature during the period measurements were being taken. To reduce the relative effect of this problem, the

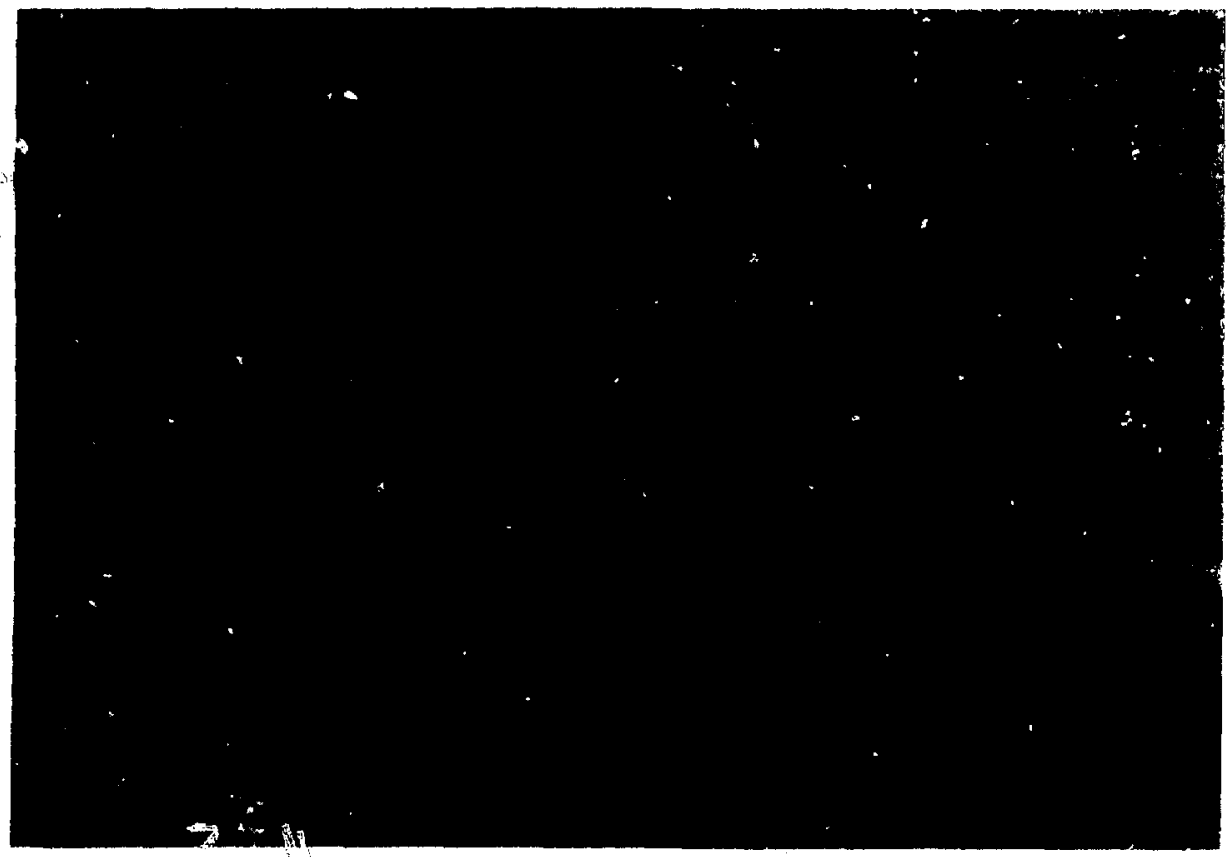

Flgure 4. The ablle cart shown coatains the megnetic anchor, two micrometers for amall dieplacemente, four aring for malutaining poittve contact with the mierometers, and a pointer and kaxrled ecrew fer postioning and securing the cart on the alnminum I-beam. The coalc probe is sorwally inserted into and throngh the aluninum guide tube that is shown paecing through the cart. 
test facility was located in a thermostatically-controlled laboratory (at LLNL). To gatn further amumice about possible temperature changes, we monitored the ahuminum I-beam at the appropriate quadrature locations ${ }^{11}$ with five thermistors. Each thermiotor was physically bonded to its station with a thermally conductive epoxy. Leads from each thermistor were electrically connected to individual chaninels of a Hewlett-Packard 3467A digital readout. Temperature readings were taken at the beginning, then at $30-$ minute intervals, and finally at the end of each series of displacement readings. Over the course of each series of readings, the largest temperature changes reconded were $\leq 0.2^{\circ} \mathrm{C}$. Theae temperature changes were small enough that no corrections were required or incorporated into the final tabulation of the displacement readings (the greatest error for the longest test interval was $<0.0005 \mathrm{in}$. [0.013 mm]).

\subsubsection{Diatance Correction Factors}

The first run was a check on the accuracy of the sonic extensometer in reconding the distance between two magnetic anchors. To conduct this test, two carts were septrated a distance of $5 \mathrm{ft}(1.5 \mathrm{~m})$, and a serles of three readings were taken. This process was repeated after moving the second cart to give separations of 10 and $15 \mathrm{ft}(3.0$ and $4.6 \mathrm{~m})$. The cart separation: were determined by means of fiberglass tape, having a least count of $0.125 \mathrm{in}$. ( $3.175 \mathrm{~mm})$, bonded to the side of the aiuminum l-beam. The fiberglass tape was checked with machinist's steel precision rule and found to be accurate to within the least count of 0.03125 in. $(0.79375 \mathrm{~mm})$ over distance of $20 \mathrm{ft}(6.1 \mathrm{~m})$. To check how accurately we positioned the carts, we repeated the above series of readings. The stock probe was subjected to the same runs as was the selected probe. In all cases, repositioning of the second cart after the first set of runs at 5,10 , and $15 \mathrm{ft}(1.5$, 3.0 , and $4.6 \mathrm{~m}$ ) gave readings that indicated the repositioning was reproducible to wiihin $0.01 \mathrm{in}$. $(0.254 \mathrm{~mm})$. Results from the above runs provided the following correction factors, $C_{f}$ for the two probes: (selected) $C_{i}=1.0213$, and (stock) $C_{i}=1.0195$. At all three distances the readings for both sonic probes were low by about $2 \%$. This means the above correction factors should be multiplied by any sonic probe reading to obtain the actual distance between the corresponding magnetic anchors. For the displacem? measurements reported here, the above correction factors add $0.001 \mathrm{in}$. $(0.0254 \mathrm{~mm})$ to those readiligs of 0.03 in. $(0.762 \mathrm{~mm})$ or larger.

\subsubsection{Displacement Measurements}

To conduct these displacement measurements, all five carts containing magnetic anchors ware located on the $20-\mathrm{ft}(6.1-\mathrm{m})$ aluminum J-beam at the appropriate quadrature locations. ${ }^{11}$ The third cart was set at the middle ( $10 \mathrm{ft}[3.0 \mathrm{~m}])$ of the I-beam and represented the null point (i.e., the micrometer settings on this cart were not changed). Then the second and fourth carts were located on either side of the third cart, each at a distance of $64.616 \mathrm{in}$. $(1.641 \mathrm{~m})$. Finally, the irst and fifth carts were spaced 44.125 in. from the second and fourth carts, respectively. In summary, the spacings between the five carts would be $44.125,64.616$, 64.616, and 44.125 in. (1.121, 1.641, 1.641, and $1.121 \mathrm{~m})$. The standard, metallic-collar anchor was not used in this series of tests because their construction varies considerably from that of the typical, polymer-body $\mathrm{C}$-anchor contained in each cart.

In the displacement results we present, only the micrometers located on carts two and four were changed. The changes were confined to these carts in order to compensate for any nonlinearities that might accompany the movement of the magnetic anchors. The nonlinearity of major concern was variability in the spring constant as movement of the magnetic anchor either compressed the four brass springs or allowed the springs to expand. For example, say we adjust the micrometers on the second cart tc move the magnetic anchor a distance of $0.005 \mathrm{in} .(0.127 \mathrm{~mm})$. In so doing, we should shorten the first interval (44.125 in. [1.121 m]) between the first two anchors by the above amount, a.id we should, at the same time, expect to Jengthen the second interval ( $64.616 \mathrm{in}$. [1.641 m]) between the second and third anchors a corresponding amount. Failure of the anchors to move the prescribed micrometer settings should be seen in both readings and provide the opportunity to compensate for the discrepancy. Although this problem occirred frequently (approximately $50 \%$ of the time), the differences generally were small-of the order of 0.001 in. $(0.025 \mathrm{~mm})$.

In conducting the displacement tests, we followed a standiard prosedure. The micrometers on the second and fourth carts were changed in the following fashion: by n,001-in. $(0.0254-\mathrm{mm})$ increments from 0.0 to 0.01 in. $(0.0$ to $0.254 \mathrm{~mm})$; by 0.005 -in. $(0.127-\mathrm{mm})$ increments from 0.01 to 0.02 in. $(0.254$ to $0.508 \mathrm{~mm})$; and by $0.01-\mathrm{in}$. $(0.254-\mathrm{mm})$ increments from 0.02 to $0.05 \mathrm{in}$. $(0.508$ to $1.270 \mathrm{~mm})$. Two $\mathrm{MB}-7 \mathrm{D}$ readings were recorded for each micrometer setting and for each interval between the magnetic anchors. Each recorded reading consisted of a mental average of about 25 different readings, taken about one 
second aprt, which appeared on the liquid-crystal dieplay following the depreasion of the pulse switch. Genwally, cach of the 25 resdinga varied only in the final digit $(0.001)$ since all 25 readings were for the same dietance between two magnetic anchors. The fact that the last digit generally was the only one that changed simplified the required mental averaging, tiut it did make the firial, adopted reading subjective. For the selected probe, the values for the final digit $(0.001)$ varied by at least two but not more than four. The corresponding variability for the stock probe was from four digits to seven digits. The range over which the 25 readings varied for the stock probe was about double that for the selected probe. This made the mental averaging for the stock probe more difficult and possibly more prone to error. However, in presenting the experimental results, we will give only the range for the subjectively averaged readings for each micrometer setting. Please note that the full range of readings we observed does not appear in Figs. 5 through 12, which present only the experimental results for the variability of the average readings.

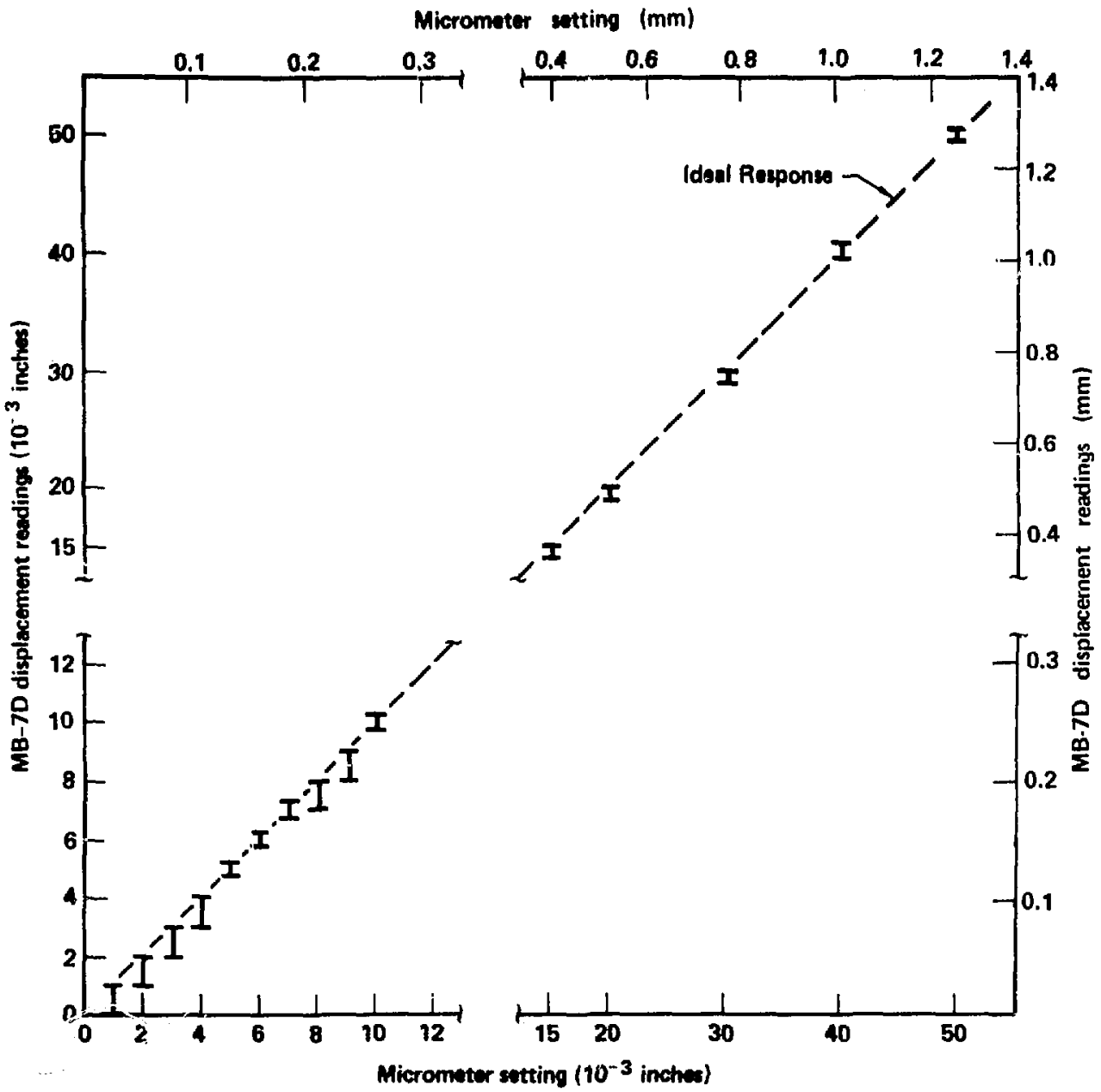

Figure 5. Range (I) of diplacement readings with the selected probe versus ihe corresponding increase in micrometer settings on the eesond cart (first and second intervaloj. The axes were broken between 0.012 and $0.015 \mathrm{in}$. $(0.305$ and $0.361 \mathrm{~mm})$, and the scales were changed to aid in the graphic presuation of the data. 


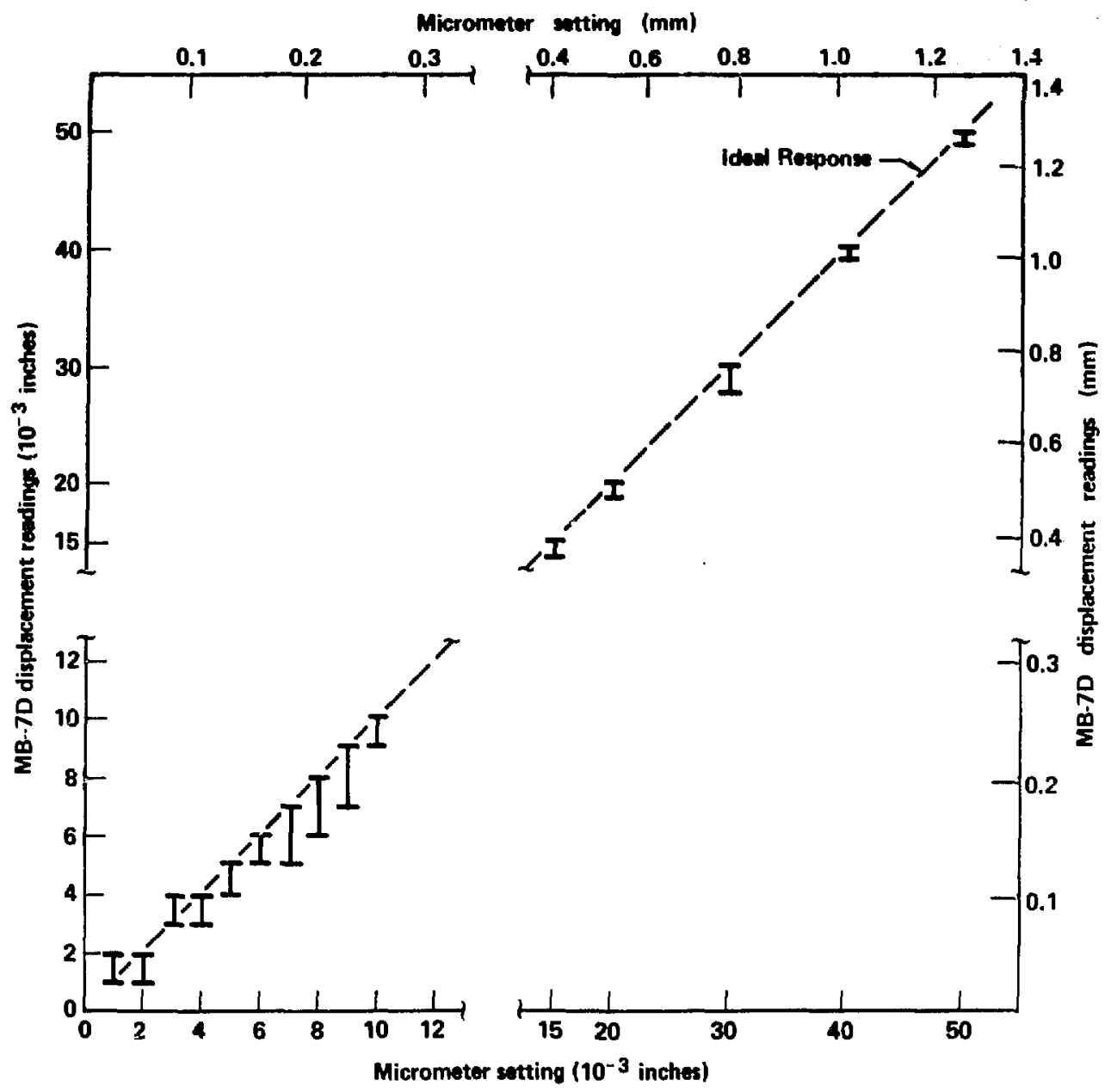

Figure 6. Range (I) of displacement readings with the selected probe yersus the corresponding increase in micrometer settings on the fourth cart (third and fourth intervals). The axes were broken between 0.012 and $0.015 \mathrm{in}$. $(0.305$ and $0.381 \mathrm{~mm})$, and the scales were changed to aid in the graphic presentation of the data.

The range of the averaged displacement readings from the MB-7D display versus the micrometer settings are shown in Fig. 5. This figure represents results for the first and second intervals as measured with the selected probe. Figure 6 shows the corresponding results for the third and fourth intervals as measured with the selected probe. The results in each figure represent the range for two intervals to compensate for displacement discrepancies due to nonlinearity in the spring constant. The results for Fig. 5 correspond to micrometer changes that shortened the first interval and simultaneously lengthened the second interval. In Fig. 6 the fourth interval was shortened and the third lengthened 1 . micrometer changes. The results displayed in Figs. 7 and 8 correspond to Figs. 5 and 6, respectively, but the direction of the micrometer movements were reversed. The springs were being compressed in Figs. 5 and 8 and were being relaxed in Figs. 6 and 7. 


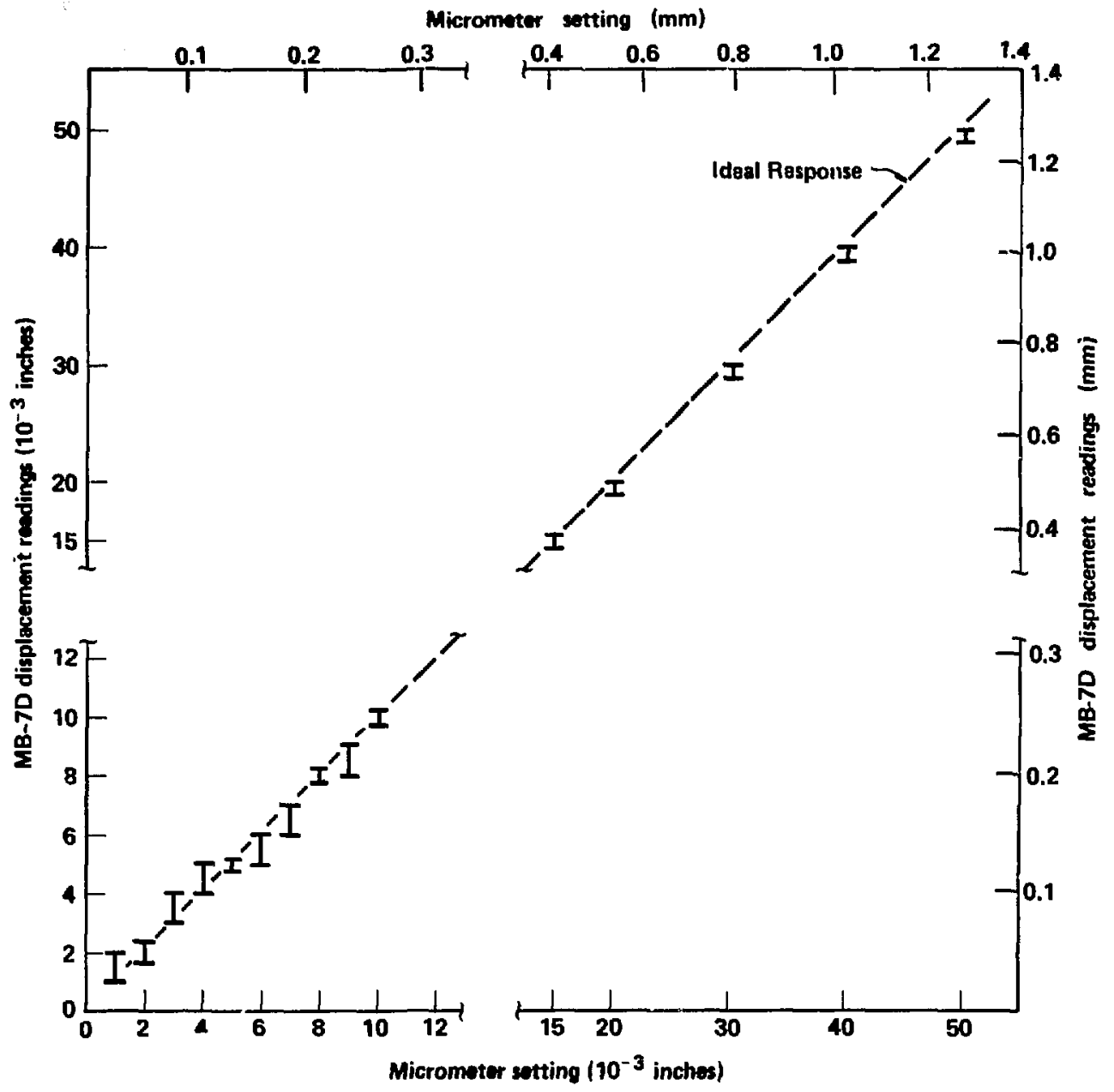

Figure 7. Range (I) of dioplacement readinge with the selected probe versus the correaponding decrease in micrometer settinga on the second cart (firt and second intervals). The axes were broken between 0.012 and $0.015 \mathrm{in}$. $(0.305$ and $0.381 \mathrm{~mm})$, and the scales were changed to aid in the graphic preaentation of the data. 


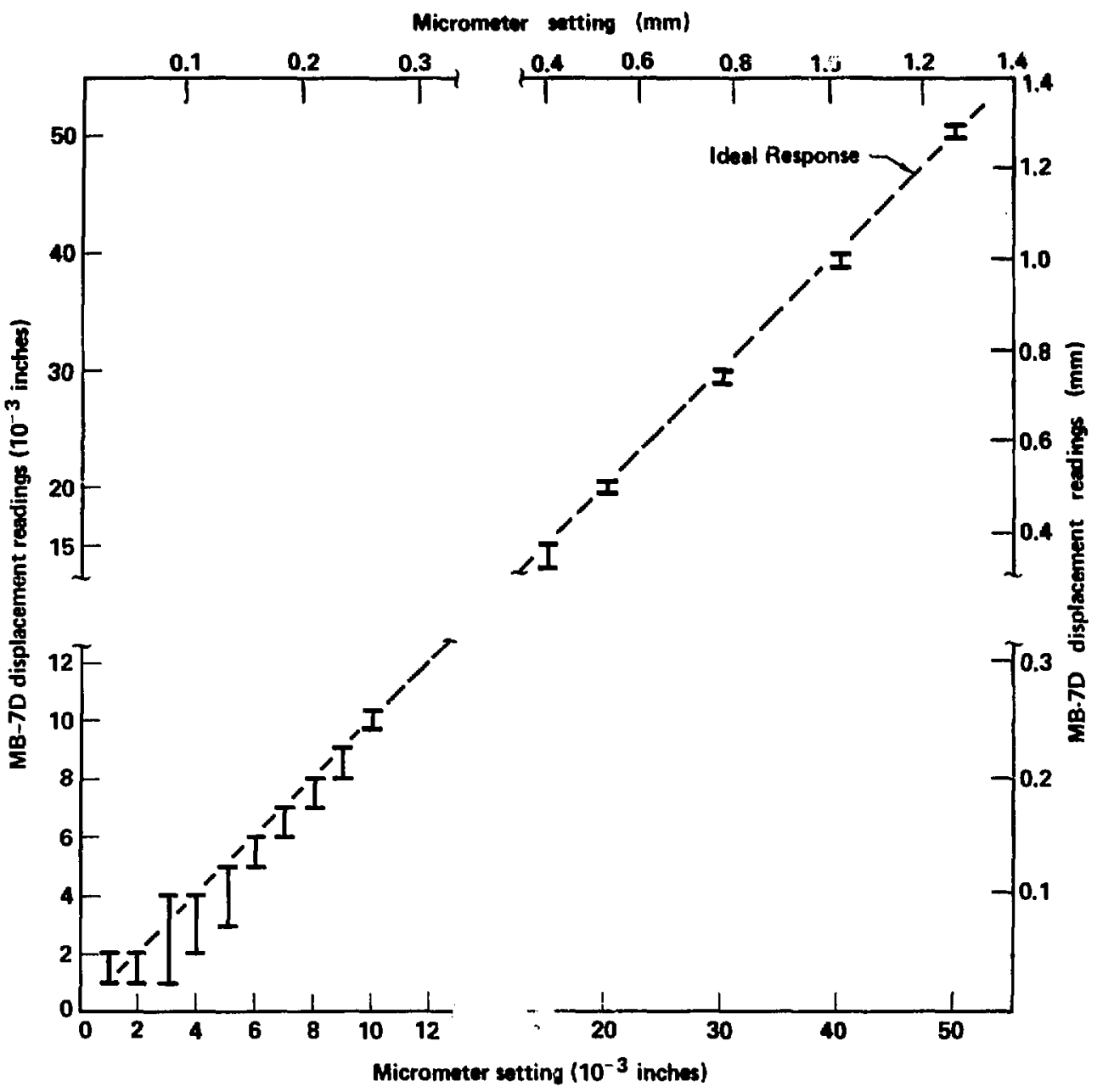

Figure 8. Range (I) of displacement readinge with the selected probe verou the corresponding decrease in micrometer settings on the fourth cart (third and fourth intervals). The axes wrere broken between 0.012 and $0.015 \mathrm{in} .(0.305$ and $0.381 \mathrm{~mm})$ and the acales changed to aid in the graphir: presentation of the data. 


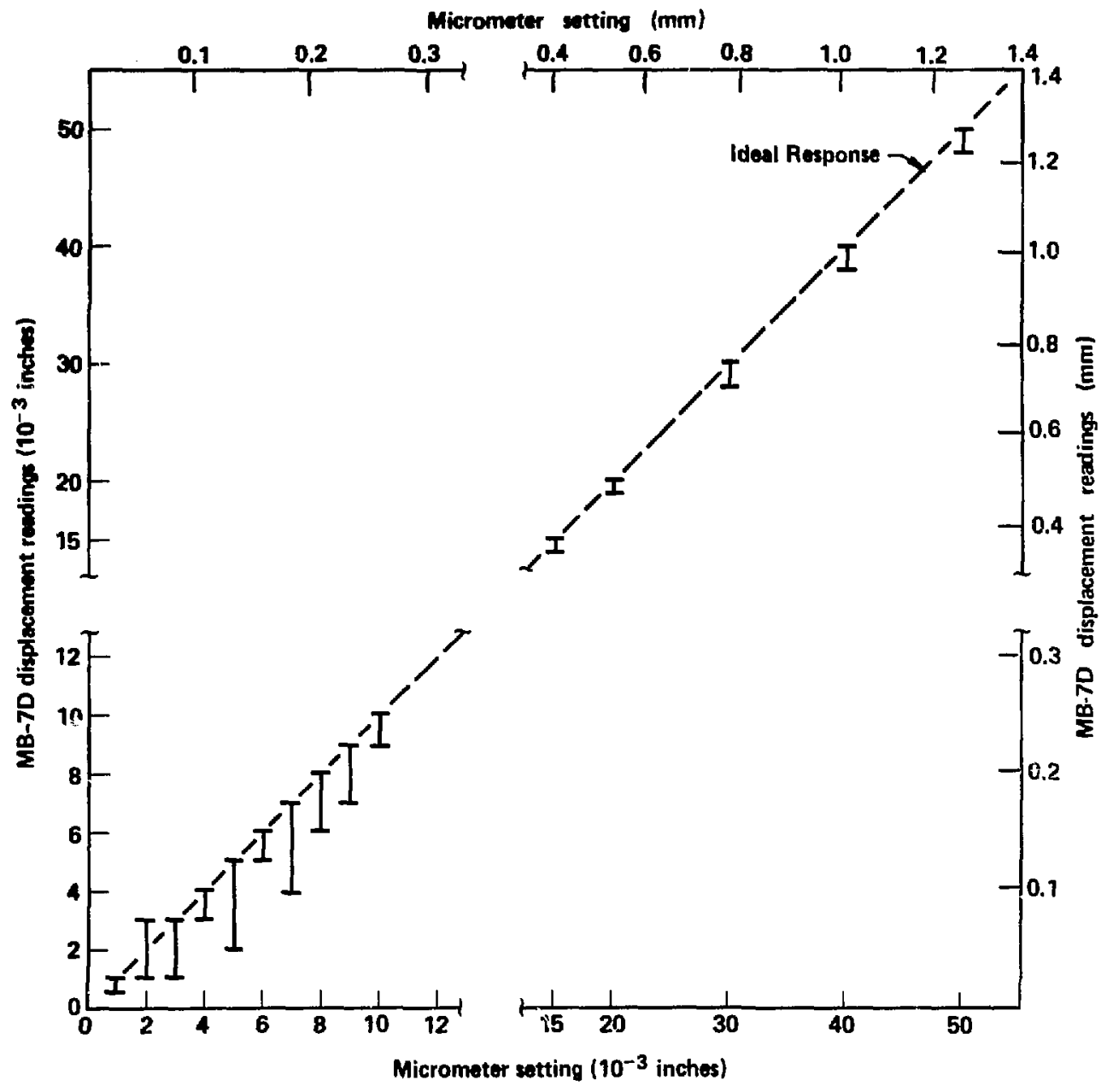

Figure 9. Range (I) of dieplacement readings with the stock probe veraus the corresponding increase in micrometer mettings on the second cart (firat and second intervals). The axes were broken between 0.012 and $0.015 \mathrm{in}$. $(0.305$ and $0.381 \mathrm{~mm})$, and the scales were changed to aid in the graphic presentation of the data. 


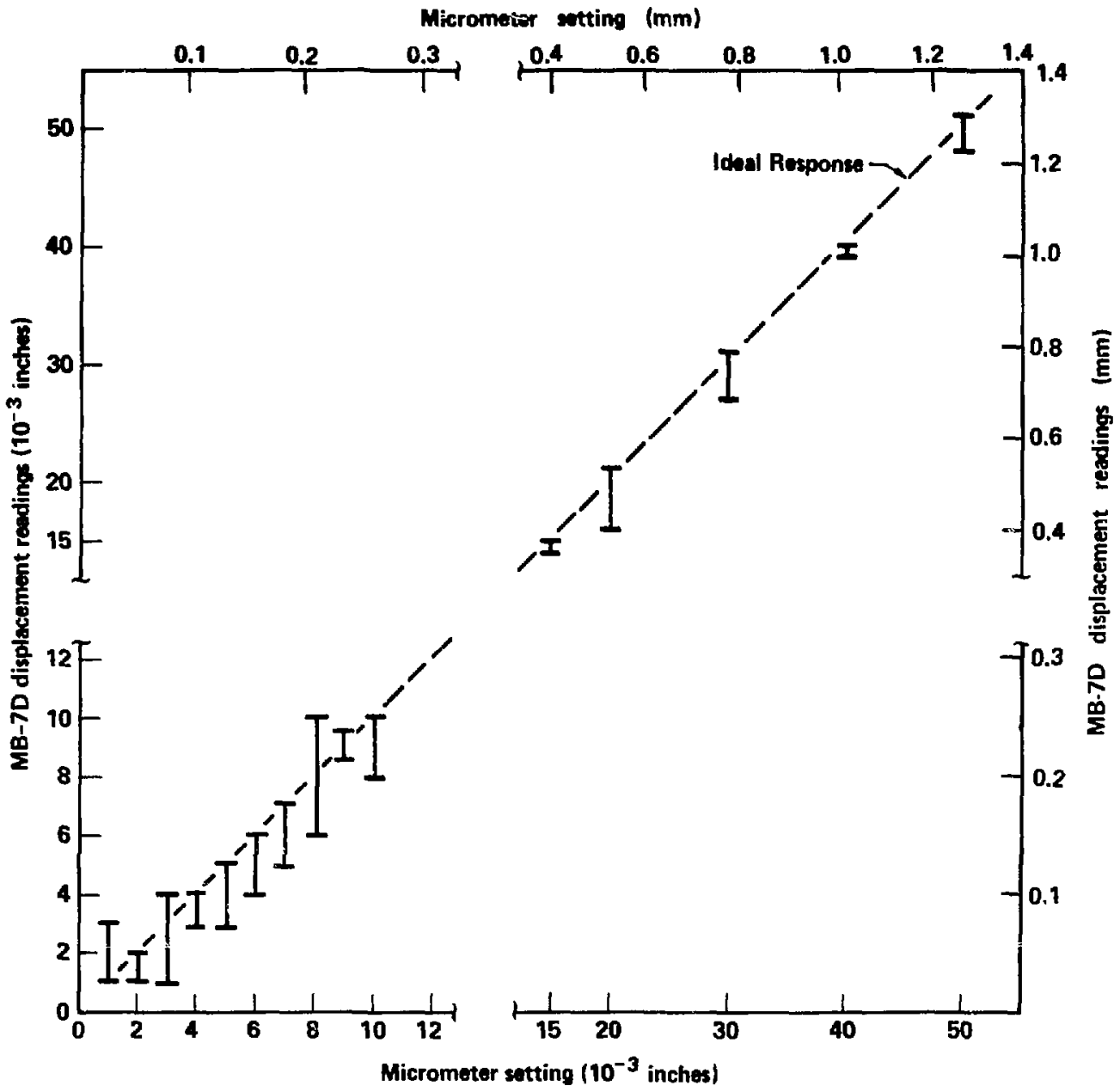

Figure 10. Range (I) of displacement readings with the stock probe versus the corresponding increase in micrometer settings on the fourth cart (third and fourth intervals). "ithe axes were broken between 0.012 and 0.015 in. $(0.305$ and $0.381 \mathrm{~mm})$, and the scales were changed to aid in the graphic presentation of the data. 


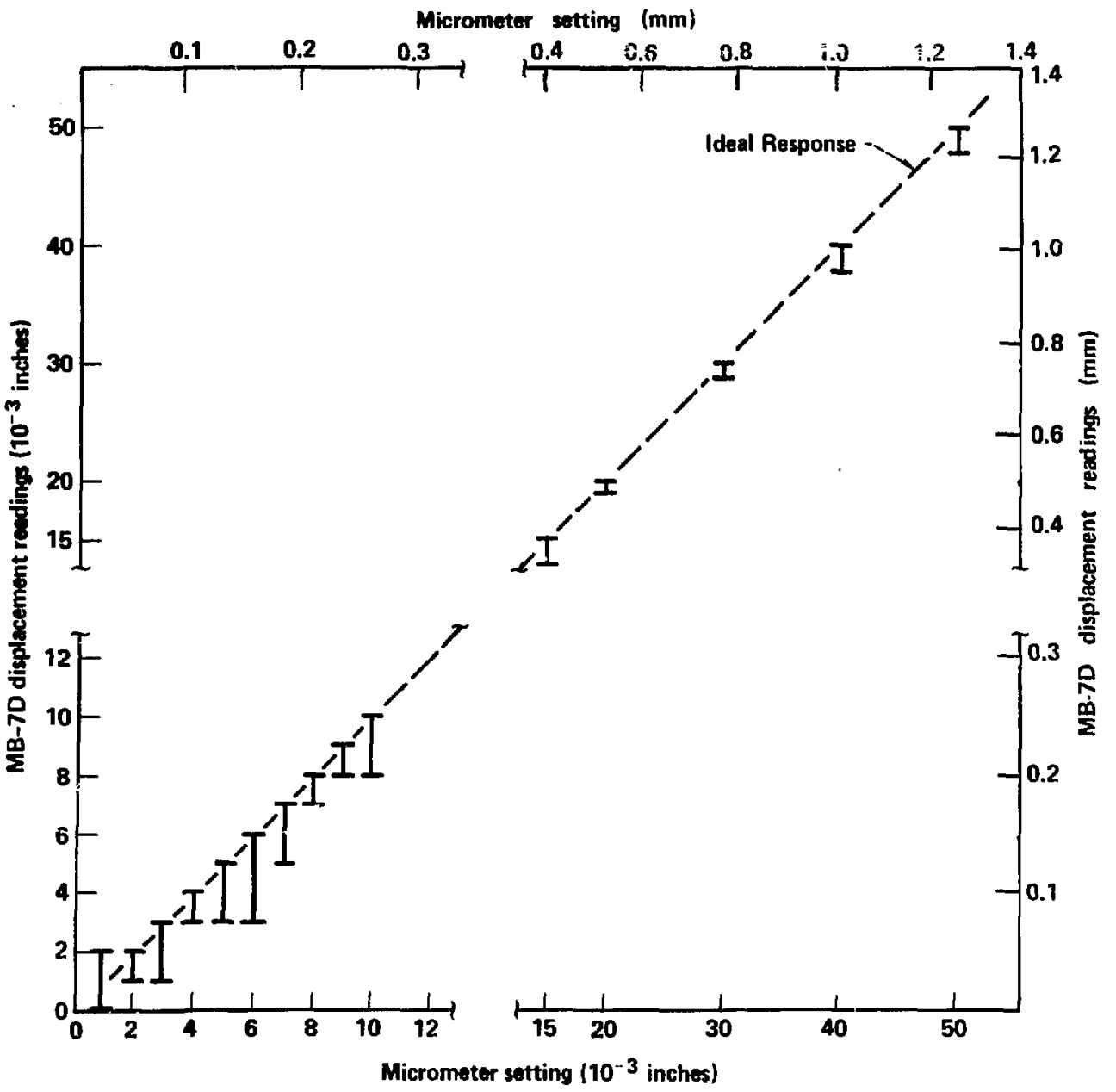

Figure 11. Range (I) of dieplacement readings with the stock probe versus the corresponding decrease in micrometer settings on the second cart (first and second intervals). The axes were broken between 0.012 and $0.015 \mathrm{in}$. $(0.305$ and $0.381 \mathrm{~mm})$, and the scales were changed to aid in the graphic presentation of the data. 


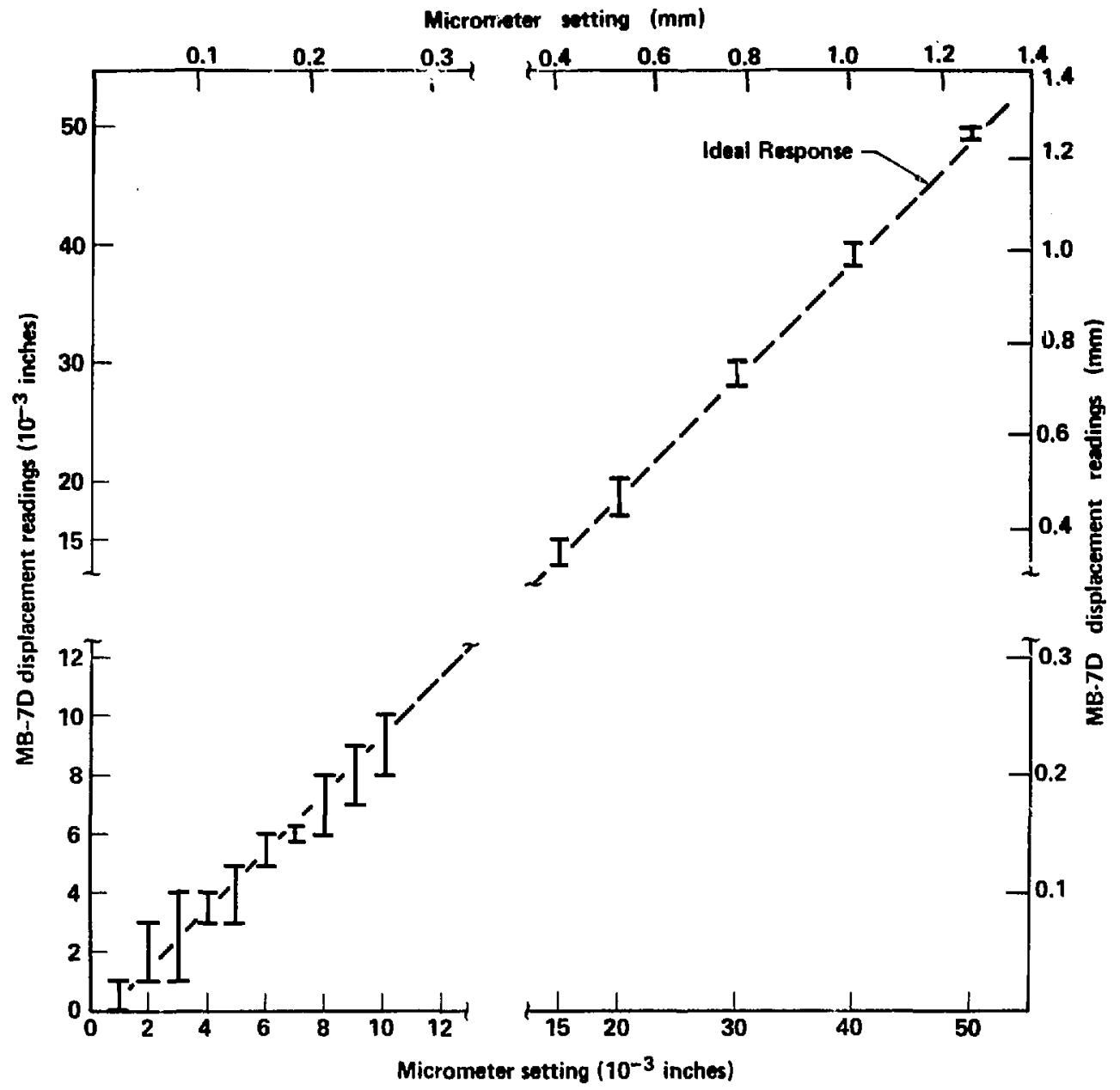

Figure 12. Range (I) of displacement readings with the stock probe versus the corresponding decrease in micrometer settings on the fourth cart (third and fourth intervals). The axes were broken between 0.012 and 0.015 in. $(0.305$ and $0.381 \mathrm{~mm})$, and the scales were changed to aid in the graphic presentation of the data. 
Understanding what is shown in Figs. 5 through 8 may require a little explanation. Let us consider two micrometer settings in Fig. 6. For a micrometer setting of $0.007 \mathrm{in} .(0.178 \mathrm{~mm})$, the magnitude of the MB-7D displacement readings in the third interval was 0.005 and $0.006 \mathrm{in}$. $(0.127$ and $0.152 \mathrm{~mm})$, and the fourth interval was 0.006 and $0.007 \mathrm{in}$. $(0.152$ and $0.178 \mathrm{~mm})$. Thus, the range for these two intervals is 0.005 to 0.007 in. $(0.127$ to $0.178 \mathrm{~mm}$ ). Similarly, for micrometer setting of $0.30 \mathrm{in}$. $(7.62 \mathrm{~mm})$, the range for the two intervals was 0.28 to $0.30 \mathrm{in}$. (7.11 to $7.62 \mathrm{~mm})$, but it appears less than the micrometer setting at 0.007 in. $(0.178 \mathrm{~mm})$ because of the scale change. Examining the four figures reveals several interesting features. The MB-7D readings have a tendency to show a value equal to or less than the micrometer settings. Variability of the readings increases with distance, i.e., the readings for the third and fourth intervals are more variable than the first and second intervals. Then there is the rather obvious fact that, although the range of the readings at the larger displacements ( 0.015 to $0.050 \mathrm{in}$. [0.381 to $1.270 \mathrm{~mm}$ ]) may be comparable to the smaller displacements $(0.0$ to $0.01 \mathrm{in} .[0.0$ to $0.254 \mathrm{~mm}])$, the percentage variability is considerably greater for the smaller displacements. The basic conclusion from the tests results is that for displacements $\leq 0.05 \mathrm{in}$. $[1.270 \mathrm{~mm}]$, the reading error is equal to or less than $\pm 0.002 \mathrm{in}$. [0.051 mm] for the selected probe.

The stock probe was subjected to the same displacement tests conducted on the selected probe. Figures 9 through 12 represent those results, and they correspond to Figs. 5 through 8, resperilvely. Recall that the stock probe was not screened, i,e., it was an off-the-shelf item. Generally, the rem.arks about the selected-probe readings can be applied to the slock probe. The basic conclusion drawn from test results for the stock probe is that, for displacements $\leq 0.05$ in. $(1.270 \mathrm{~mm})$, the reading error is equal to or less than \pm 0.003 in. $(0.076 \mathrm{~mm})$ The greater accuracy of the selected probe is readily evident when the two sets of figures for thet twe probes are compared.

\subsection{Sensitivity to High-Explosives Shocks}

Portions of the IRAD extensometer system may be subjected to harsh invironments for long periods of time during iield measurements in underground applications. The sonic probe is normally not exposed to harsh environments for significant periods of time since it is inselted into the borehole just prior to each measurement and removed promptly thereafter. Generally only the magnetic anchors (and possibly the guide tube) remain permanently in the borehole after their installation. An example of the harsh environment possible is strong shocks from chemical explosives used in mining or excavating close to the borehole during early phases of construction. Since we must often measure displacements very near an excavated face, we must be concerned about the possible shock effects on the integrity of the magnetic anchors. We describe here a series of high-explosives (HE) tests made to investigate the effect of strong shocks on these anchors.

\subsubsection{Experimental Procedure for the High-Explosives Tests}

The experimental plan for examining the IRAD extensometer system's response to strong shocks is illustrated in Fig. 13. This geometry is based on preshot finite-difference caiculations that are described later. An approximately 1.5-in.-diam (38-mm) boreh.le ('ST1) used for sloock testing was drilled with a jackleg to a depth of $22 \mathrm{ft}(6.71 \mathrm{~m})$. This hole was initially intended to be used to emplace the anchors, but it was found (when measured with gage blocks) to be somewhat oversized for that purpose. Instead of magnetic anchors, the hole was instrumented with a ratial accelerometer at a depth of $11.0 \mathrm{ft}(3.35 \mathrm{~m})$ from the tunnel wall. This radial accelerometer (RA5) was oriented to resasure the radial shocks from line charges placed in parallel boreholes. A second borehole (ST2) with a $1.5 \mathrm{in}$. (38 mm) diam was core drilled parallel to, but 6 in. $(150 \mathrm{~mm})$ below, the first borehole; it also had a depth of $22 \mathrm{ft}(6.71 \mathrm{~m})$. This borehole was instrumented with five magnetic anchors at the quadrature positions over a $16 \mathrm{ft}(4.88 \mathrm{~m})$ interval centered at a depth of $10.85 \mathrm{ft}(3.31 \mathrm{~m})$ from the free surface. These dimensions were chosen so that the first and fifth magnetic anchors were well away from the tunnel walls and the high explosives used in another test (to be described later) in which we generated a shock that propagated along the axis of the borehole. Following placement of the magnetic anchors, the guide tube was inserted and the collar anchor installed at the collar of the borehole. Parallel boreholes to be used for HE charges were drilled at distances of $1,2,4$, and $8 \mathrm{ft}(0.31,0.61,1.22$, and $2.44 \mathrm{~m})$ from the tho instrumented holes. The first hole was core-drilled to permit precise alignment while the remaining three holes were rotary-percussion drilled with a jackleg. These HE boreholes all had $1.5 \mathrm{in}$. $(38 \mathrm{~mm})$ diameters with $22 \mathrm{ft}(6.71 \mathrm{~m})$ depths and 

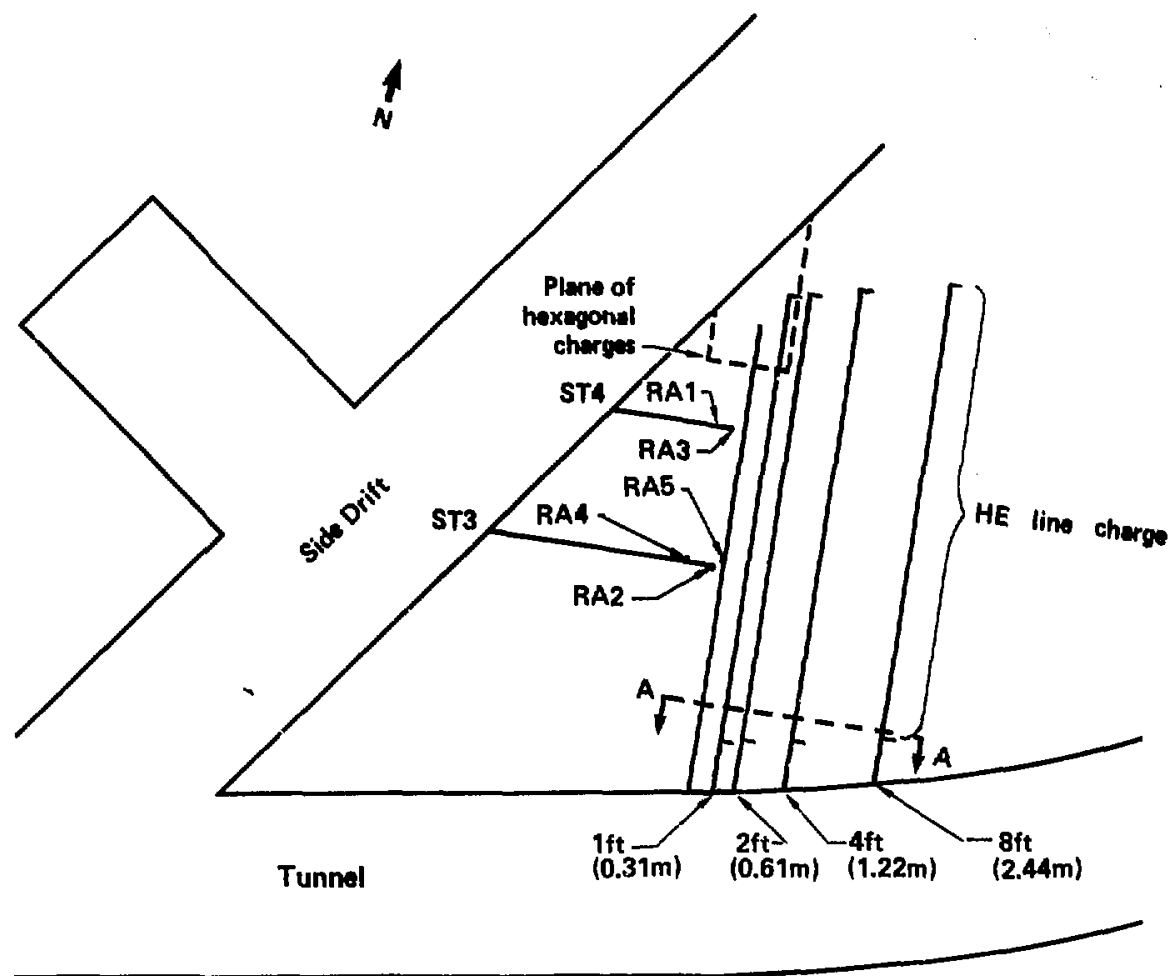

Horizontal plan viow

O ST1 (RA5 Gage Borcholo)

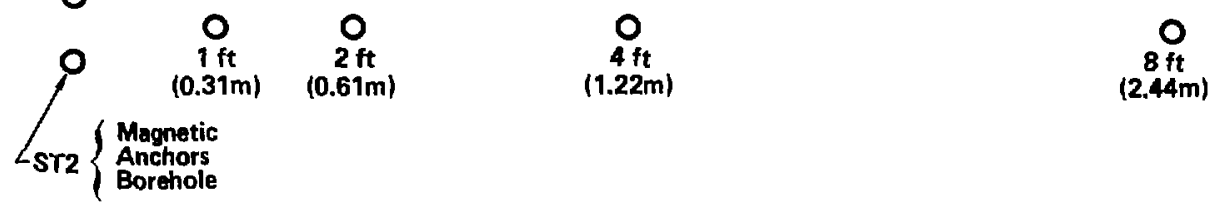

Vertical section view-Section A-A

Figure 13. Experimental plan for teating the IRAD-exten.someter system to strong shock effects. The location of the five radial accelerometers (RA) and the four shock-teat (ST) boreholes is illustrated. 
were located in a horizontal plane passing through the midpoint between the two instrumented holes, ST1 and ST2 (Fig. 13).

A small-scale version of the HE-test series was conducted about one montit earlier. The small-scale tests confirmed our choice of accelerometers $(50,000 \mathrm{~g})$ but also raised concerns about surface spalling and shock effects on cabling. Although only about six sticks of Unigel were detonated in each small-scale test, in one test the orientation of geologic fractures caused lateral surface spalling along the wall of the tunnei in one direction for a distance greater than $4 \mathrm{ft}(1.22 \mathrm{~m})$. This raised concern that cables exiting the instrument hole might be severed as the tunnel wall spalls after detonation. In addition, the accelerometer records appeared to be noisy, and it was thought that the shock wave impacting the cables might be inducing part of the noise.

To eliminate or significantly reduce these effects in the full-scale experiment, two additional instrument holes (ST3 and ST4) were core drilled from the face of the side drift. These boreholes were perpendicular to but in the same horizontal plane as the instrumented borehole (ST2) containing the five magnetic anchors. Two of the accelerometers originally intended for the ST1 borehole were shifted to these two instrumented holes. To retain the same radial orientation to the line charges (e.g., as for RA5), the two accelerometers (RA2 and RA3) were mounted flush against the end of each borehole. Accelerometers RA2 and RA3 were 0.64 and $0.71 \mathrm{ft}(195$ and $216 \mathrm{~mm})$, respectively, from the center of the borehole containing the the magnetic anchors.

Figure 14 illustrates the configuration of a HE test to study postshot effects on the MB-7D readings following shock propagation along the axis of the borthole containing the magnetic anchors. For this test, accelerometers RA4 and RA1 were located $0.3 \mathrm{ft}(91 \mathrm{~mm}$ ) from RA2 (in borehole ST3) and RA3 (in borehole ST4), respectively. Accelerometers RA4 and RA1 were oriented to monitor axial acceleration from the detonation of a hexagonal array of $\mathrm{HE}$ charges located in boreholes which were jackleg drilled into the wall of the side drift. The boreholes were at 60-dey azimuthal intervals on the circumference of a 6-ft-diam $(1.83-\mathrm{m})$ circle inscribed on the face of the side drift. A single stick of Unigel with detonation cap was tamped inio place at the end of each borehole. The volume of the borehole between the $H E$ and face of the side drift was stemmed with sand to help contain the $\mathrm{XEE}$ gases. The six boreholes were drilled to depths such that the end of each charge was in a plane perpe:ndicular to the magnetic-anchor borehole. The hexagonal array of charges was positioned so that its central axis bisected the distance between the magnetic-anchor borehole and the radial accelerometer (RA1) in ST4. The plane of the charige was about $3.5 \mathrm{ft}$ and $9.5 \mathrm{ft}(1.07$ and $2.90 \mathrm{~m}$ ) from RA1 (in ST4) and RA4 (in ST3), respectively. In an attempt to simulate a plane-wave shock, we fired the six charges simultaneously with electric caps.

\subsubsection{Experimental Results of High-Explosives Tests}

The line charge at $8 \mathrm{ft}(2.44 \mathrm{~m})$ from boreholes ST1 and ST2 was detonated in the first HE test. The hexagonal array was detonated in the second HE test to examine axial-shock loading of the magnetic anchors in ST2. Then the line charges at 4,2 , and $1 \mathrm{ft}(1.22,0.61$, and $0.31 \mathrm{~m})$ from boreholes ST1 and ST2 were shot in a sequence of separate tests. The line charge at $2 \mathrm{ft}(0.61 \mathrm{~m})$ produced small rock fragments and caused a small amount of rock dist to appear in the borehole at $1 \mathrm{ft}(0.31 \mathrm{~m})$. However, we cleaned this borehole with compressed air before emplacing the line charge for the $1-\mathrm{ft}(0.31-\mathrm{m})$ test. We first give the results of the line-charge experiment and then the results for the hexagonal-array experiment.

The peak acceleration values from line-charge detonations at 8,4 , and $2 \mathrm{ft}(2.44,1.22$, and $0.61 \mathrm{~m})$ are shown in Fig. 15. The solid triangles on this graph represent radial-acceleration measurements obtained during bench blasting for the canister drift at the Climax facility. ${ }^{12}$ The dashed line drawn through the acceleration data is an extrapolation of the solid line, which was taken from Ref. 12, p. 7; the dashed line appears to fit all the experimental results. The results for RA3 are consistently higher than the results for the other two stations. This may be due partially to the fact that RA3 is located further from the free surface and, therefore, has raduced rarefaction effects. Gages RA2 and RA3 were installed flush against the flat end of the boreholes, while RA5 would not have been in as good contact with the side wall of the ST1 borehole because of its 0.75 -in. $(19-\mathrm{mm})$ radius of curvature. Whether this difference in mounting procedure affected the shock coupling remains primarily conjectural since the results for RA2 are lower than RA5 for the shots at 8 and $4 \mathrm{ft}(2.44$ and $1.22 \mathrm{~m})$ and higher at $2 \mathrm{ft}(0.61 \mathrm{~m})$. The abnormally low response for RA5 at $2 \mathrm{ft}(0.61 \mathrm{~m})$ may be due to the presence of microcracks induced by the shock wave since RA5 is closer than RA2 by $0.68 \mathrm{ft}(207 \mathrm{~mm})$ to the $2 \mathrm{ft}(0.61 \mathrm{~m})$ line charge.

Three radial accelerometers (RA2, RA3, and RA5) failed immediately following arrival of the shock wave from the detonation of the line charge at $1 \mathrm{ft}(0.31 \mathrm{~m})$. Postshot examination of the magnetic-anchor borehole (ST2) indicated the hole closed at a distance of $7.46 \mathrm{ft}(2.27 \mathrm{~m})$ from the tunnel wall. No remnants 


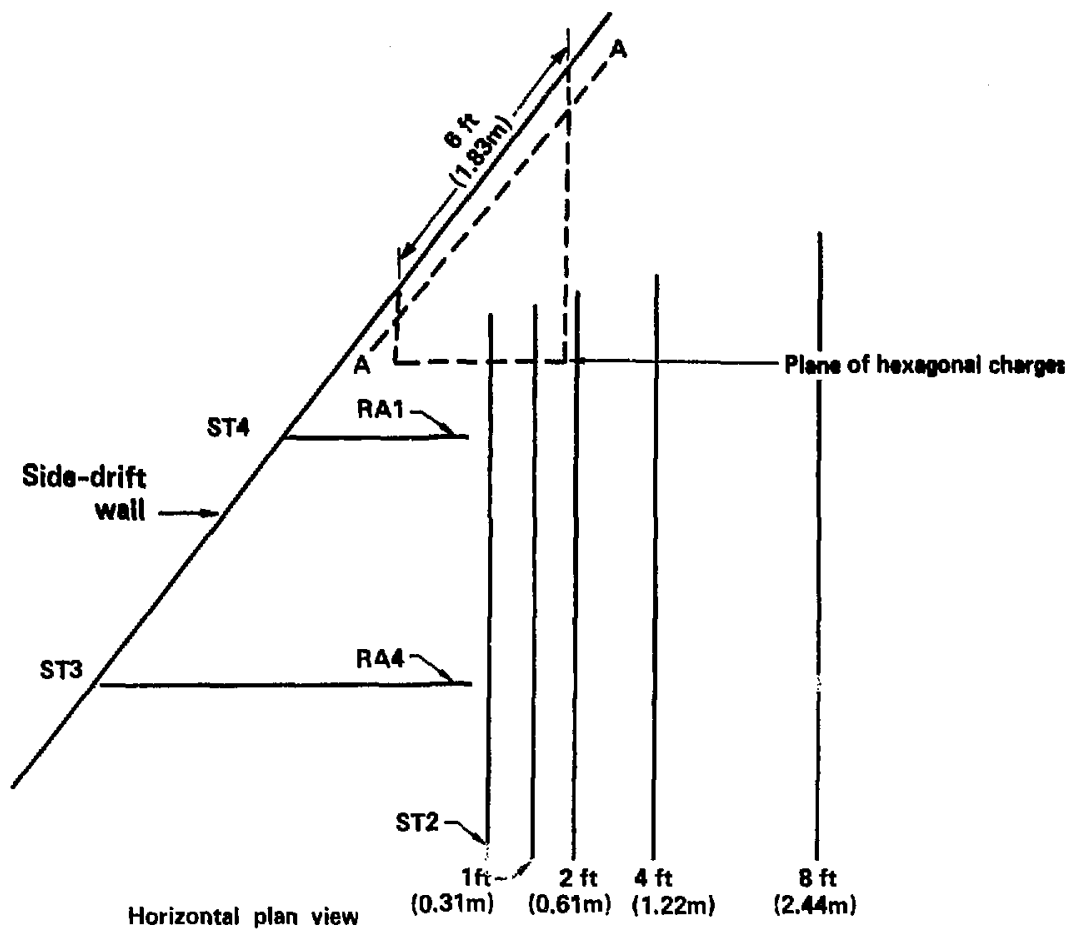

Horizontal plan view

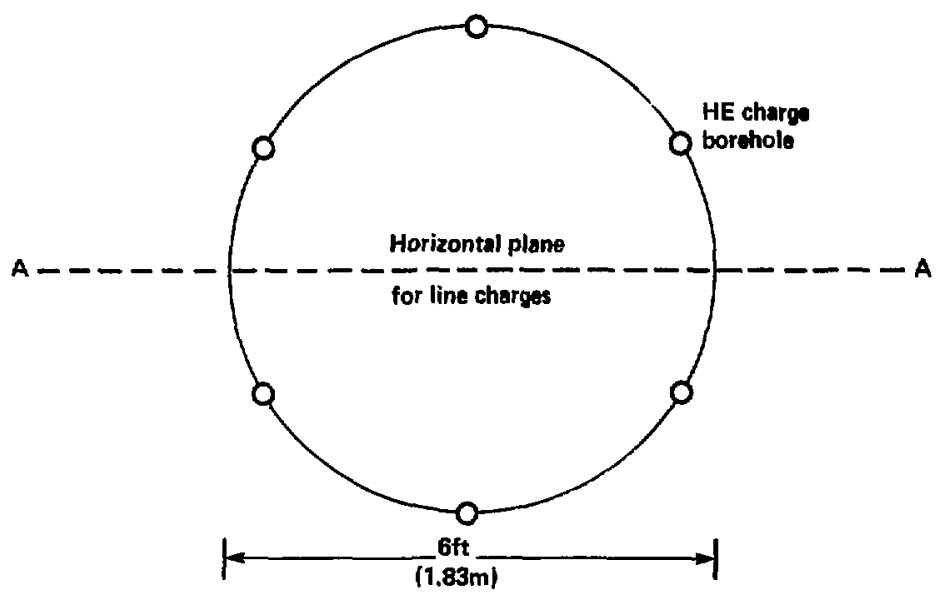

Vertical section view Section A.A

Figure 14. Hexagonal array of charges used to study axial shock loading of the megnetic-anchor borehole (ST2). 


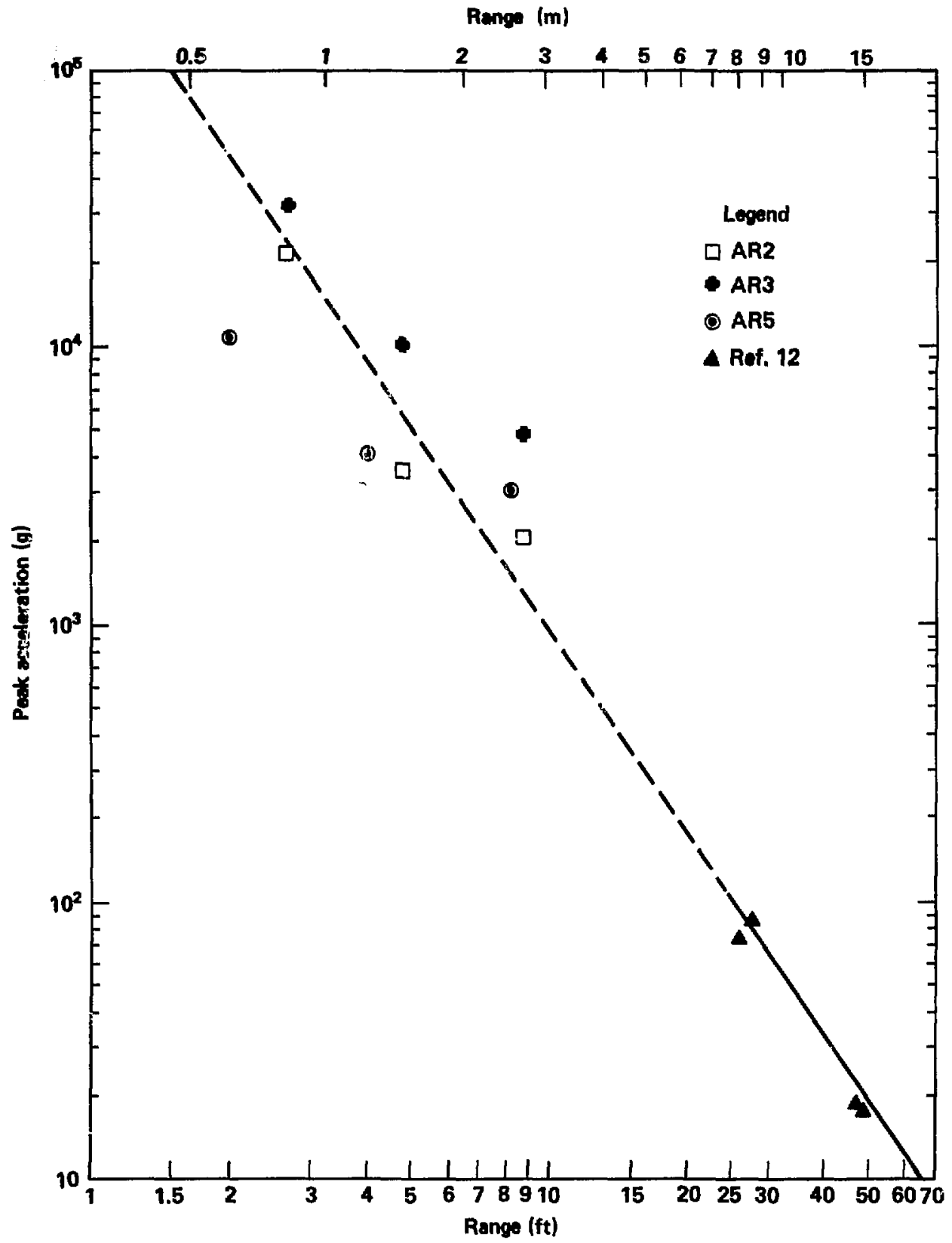

Figure 15. Feak acceleration vereus range from line charges of high explosives. 
or fragments of the magnetic anchors, located at 3.60 - and $6.54-\mathrm{ft}(1.10$ - and $1.99-\mathrm{m})$ depthe from the tunnel face, were seen in ST2. The hole appeared to be blown free of all debris and duet. Wh hypotheute: that the ground shock pulverized both anchors, and then their fragments were blown into the turnel by air extruded as tile last $\simeq 14.5 \mathrm{ft}(4.42 \mathrm{~m})$ of the borehole closed. The turnel floor was strewn with too much spalled rock to find any small fragments of the magnetic arishors that may have been preserit.

Before detonating the HE, we needed to know how extensively the shock wave might damage the surrounding granite. Therefore, preshot calculations ${ }^{13}$ were performed with the one-dimentional, finitedifference code, SOC. ${ }^{14}$ To simulate the line-charge detonation, the calculations were run in cylinetical geometry, and the Jones-Wilkins-Lee parameters were used to describe the expansion isentropes for Unigel. Figure 16 shows plots of the damage parameter, $\epsilon_{\mathrm{fs}}$, for values of shear-strain-induced failure of 1 and $10 \%$. These have been shown to correspond to radii within which observable damage $(1 \%)$ and total damage $(10 \%)$ occur. Observable damage is characterized by microfracturss and total damage by disaggregation. These distances scale with cavity radius. These predictions convinced us not to space the line charges closer than $1 \mathrm{ft}(305 \mathrm{~mm})$ apart.

Fig're 17 represents predicted radial expansion versus time and the range of the final, measured borehole radius following the detonation. By $2 \mathrm{~ms}$ the cavity has reached its maxinum radius of $44.2 \mathrm{~mm}$. Following the line-charge detonation at $1 \mathrm{ft}(0.31 \mathrm{~m})$, the tunnel wall had spalled to a depth of $2.25 \mathrm{ft}$ $(0.69 \mathrm{~m})$ in the vicinity of the previously fired $2-\mathrm{ft}(0.61-\mathrm{m})$ line charge. This deptlt ot spall exposed the $2-\mathrm{ft}$ $(0.61-\mathrm{m})$ borehole sufficiently to allow cavity-radius measurements. The cavity radius at that depth ranged between 1.625 and $1.75 \mathrm{in}$. ( 41.3 and $44.5 \mathrm{~mm}$ ). This range is plotted on the right side of the graph and compares favorably with calculational results at $2 \mathrm{~ms}$. Farther along the borehole, away from the former tunnel wall and rarefaction effects, the cavity radius might even be slightly larger and agree bettel with calculations.

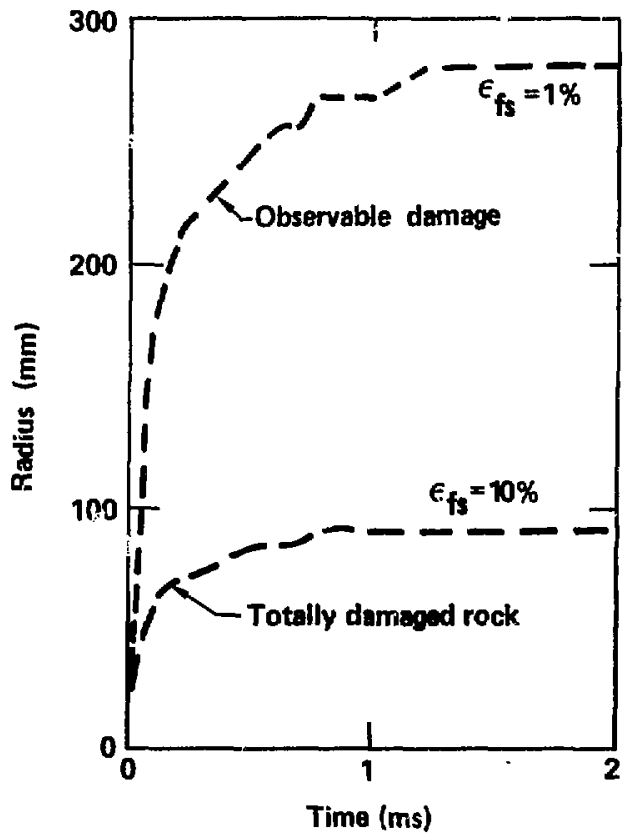

Figure 16. Shock-induced damage in the granite showing radial extent versus time after detonation from one-dimensional, finite-difference calculations. The values of shear-atrain-induced fallure, $f_{f o r}$ of 1 and $10 \%$ correspond to radii where observable damage and total damage occur, respectively. 
Hige 17. Cavity radius verasts the diver detonation.

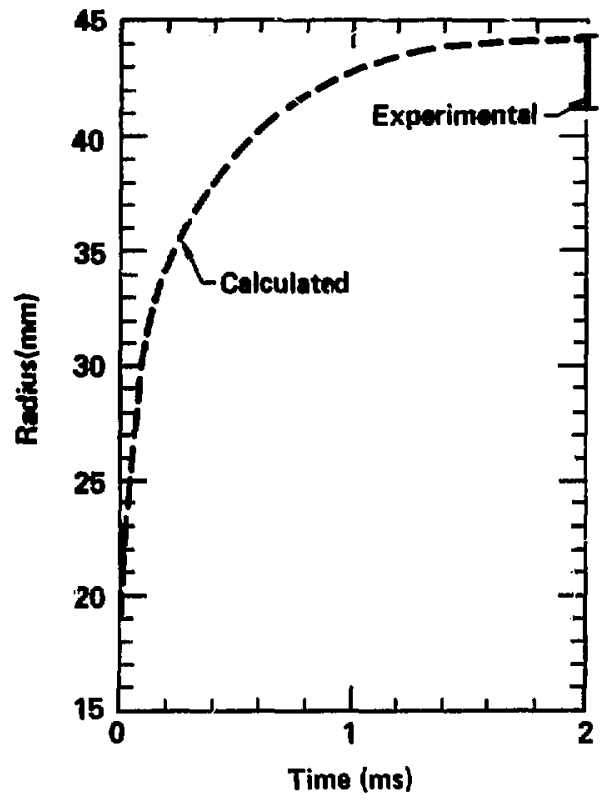

Before and after each HE detonation, the IRAD sonic probe was inserted and MB-7D readings were taken of the distance between the adjacent magnetic anchors. The MB-7D readings after the shots were delayed 30 minutes or more to give time to clear $t_{i}:$ ara of dust and fractured rock at the tunnel wall and ceiling near the detonated charges. The preshot and wishot readings are given in Table 4. For the 2-ft (0.61-m) line charge, the collar anchor and guide tube were removed before the shot. The collar anchor was removed to prevent possible damage from surface spall. The guide tube was removed parially for the same reason. In addition, the guide tube was supported by the magnetic anchors and, therefore, did not come in contact with the walls. Consequently, there was some concern that the high accelerations at the magnetic anchors might give them sufficient inertial force to crimp the guide tubes. The preshot removal and postshot replacement of the collar anchor and guide tube may have contributed to the consistent 0.004- to 0.006-in. (0.102- to 0.152-mm) shift in the readings for the first three intervals before and after the shot. The 'aluch larger shift of 0.015 to 0.016 in. $(0.381$ to $0.406 \mathrm{~mm})$ in the readings for the fourth interval probably represent the effects of shock-induced strain or microcracks in the granite. The preshot and postshot readings for the $8-$ and $4-\mathrm{ft}(2.44$ - and $1.22-\mathrm{m})$ line charges differ by 0.002 to 0.003 in. $(0.051$ to $0.076 \mathrm{~mm}$ ). This variability is approximately within the $\pm 0.002 \mathrm{in} .(0.051 \mathrm{~mm})$ cited for the IRAD sonic probe. However, if we compare the preshot readings at $8 \mathrm{ft}(2.44 \mathrm{~m})$ with the pieshot readings at $2 \mathrm{ft}(0.61 \mathrm{~m})$, then a definite trend can be seen. The first and third intervals appear.$u$ be within the acusracy bounds, but the second and fourth intervals appear to have increased, perhaps because of shock effects on the rock from detonation of the 8- and 4-ft (2.44- and 1.22-m) line charges.

In order to generate a plane shock in the axial direction along the magnetic-anchor borehole (ST2), we arrayed six sticks of Unigel (about one-third of that used for the line charges) in a hexagonal pattern. The MB-7D readings taken after the shot indicated no effect from the detonation. The lower preshot readings ( $0.003 \mathrm{in}$. [ $6 \mathrm{~mm}$ ) for the first readings are probably within the accuracy of the system. These results are not surprisii.g, considering the relative weakness of the charges. Timing and amplitude uncertainties for the radial accelerometers (RA4 and RA1) were too large to provide reliable results from these gages. Spalling of rock from the wall of the side drift and damage to the HE boreholes made it impractical to consider more than one such HE test. 
Table 4. Magnetic-anchor dieplacementa turing high-expledives wets conductal in Climax granthe at the Nevada Teat Site. Readings, taken from the MB-7D readout box before and efter each detoantiea, are expresed in inches, the primary unit of measure for this indrument. The fint MI-7D realing in this table are given in full, but the digits to the left of the decimal are conlted fren suburquent readinge for brevity.

\begin{tabular}{|c|c|c|c|c|c|c|c|c|}
\hline \multirow[b]{2}{*}{ Interval } & \multicolumn{2}{|c|}{ O-ft shot } & \multicolumn{2}{|c|}{ toft shet } & \multicolumn{2}{|c|}{ 2-ft shet } & \multicolumn{2}{|c|}{ Hexe panl array } \\
\hline & $\begin{array}{l}\text { Preshod } \\
\text { (In.) }\end{array}$ & $\begin{array}{c}\text { Postichote } \\
\text { (In.) }\end{array}$ & $\begin{array}{l}\text { Problotd } \\
\text { (In.) }\end{array}$ & $\begin{array}{l}\text { Rowlinet } \\
\text { (in.) }\end{array}$ & $\begin{array}{c}\text { Prentuet } \\
\text { (ine) }\end{array}$ & $\begin{array}{c}\text { Pouthers } \\
\text { (In) }\end{array}$ & $\begin{array}{l}\text { Preshet } \\
\text { (in.) }\end{array}$ & $\begin{array}{l}\text { Roubluot } \\
\text { (In) }\end{array}$ \\
\hline 1 & $34.535-.536$ & $.555-.555$ & $.355-.555$ & $.530-.359$ & $.358-5 s$ & $.562-.363$ & $.553-.553$ & $3 x-35$ \\
\hline 2 & $50.877-.897$ & $.820-.800$ & $.051-.051$ & $.081-.812$ & $.028-102$ & $.6 \times-1.045$ & $.00-100$ & 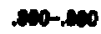 \\
\hline 3 & $50.492-.492$ & $.495-.493$ & $.4 \%-.4 M$ & $.483-.443$ & $.48-.48$ & $.4 \%-45$ & 49s-dis & Atz- 491 \\
\hline 4 & $34.611-, 610$ & $.613-.613$ & $.613-.613$ & $.015-.615$ & $.616-.616$ & $.632-.631$ & $.613-.613$ & $.612-.513$ \\
\hline
\end{tabular}

Collar anchor and gulde tube removed before the thot and reinarted atter the shot.

b Readinga taken at 1430 hours on 3/20/84.

C Readinge taken at 0900 houre on 3/21/84.

"Readinge taken al 0300 hours on 3/22/84.

- Readings taken at $\simeq 2.5$ hours after the shot on $3 / 22 / 04$.

f Readinge taken at 1300 houre on 3/22/84.

8 Readings taken at 30 minutes after the shot on $3 / 22 / 84$.

$h$ Readinge taken 1300 hours on 3/21/O4.

i Readinga taken at $\simeq 1.5$ hours after the shot on $3 / 21 / 84$.

\subsection{Sensitivity to Temperature Changes}

In addition to strong shock response, the temperature sensitivity of the IRAD sonic extensometer must be better understood if it is ' $O$ be used in environments in which changes in temperature may occur during the course of the experiment. For this purpose a temperature bath was designed (Fig. 18) that could be varied over a range of 20 co $50^{\circ} \mathrm{C}$ and maintain a uniform temperature over its length to within $\pm 0.1^{\circ} \mathrm{C}$. The test range was confined to 20 to $50^{\circ} \mathrm{C}$ because that is the range anticipated during in situ, elevated-temperature tests of large rock masses (such as pillars between storage drifts). As previously suggested, ${ }^{8}$ the temperature bath was used in conjunction with the bench-test facility used to conduct the tests of displacement accuracy for this study. We first give the details of the experimental setup and procedure and then present the results of the temperature runs.

\subsubsection{Experimental Setup and Procedure}

Fabrication of the temperature bath began with two long aluminum tubes. The smaller tube was $22 \mathrm{ft}$ $(6.71 \mathrm{~m})$ long and had an outside diameter of $7.5 \mathrm{in} .(190 \mathrm{~mm})$ and a wall thickness of $0.25 \mathrm{in} .(6.4 \mathrm{~mm})$. It was placed inside a second tube $24 \mathrm{ft}(7.32 \mathrm{~m})$ long, $12.0 \mathrm{in}$. (305 mm) o.d., and $0.25 \mathrm{in}$. (6.4 mm) thick. Spacers were located so that the two tubes would be concentric. Circular aluminum plates were used to secure the ends of each tube and isolate their interiors from one another. The 2-in. (50.8-mm) space between the two tubes was filled with water. $A$ heat tape, wrapped in a spiral around the outer tube, was used to raise and control the temperature of the interior. The purpose of the water was to moderate temperature changes inside the inner tube. Finally the outer tube was wrapped with fiberglass insulation to reduce heat losses.

The I-beam test bed, used for the displacement measurements, was inserted inside the inner tube. The temperature inside the center tube was monitored with five thermistors attached to the I-beam at the five quadrature positions where the carts containing the magnetic anchors were located. A sixth thermistor at the center of the I-beam (third quadrature position) was used to regulate the temperature of the interior by means of a loop controller and the heat tape. The other five thermistors were used to provide a periodic record of the I-beam temperature and degree of uniformity of the temperature along the I-beam. The six thermistors and the digital-readcut system (Hewlett-Packard 3467A) used to record the temperatures were given calibration checks at our temperature laboratory. Calibration was checked before and after the temperature tests and was factored into the data reduction and analysis of the temperature results. 


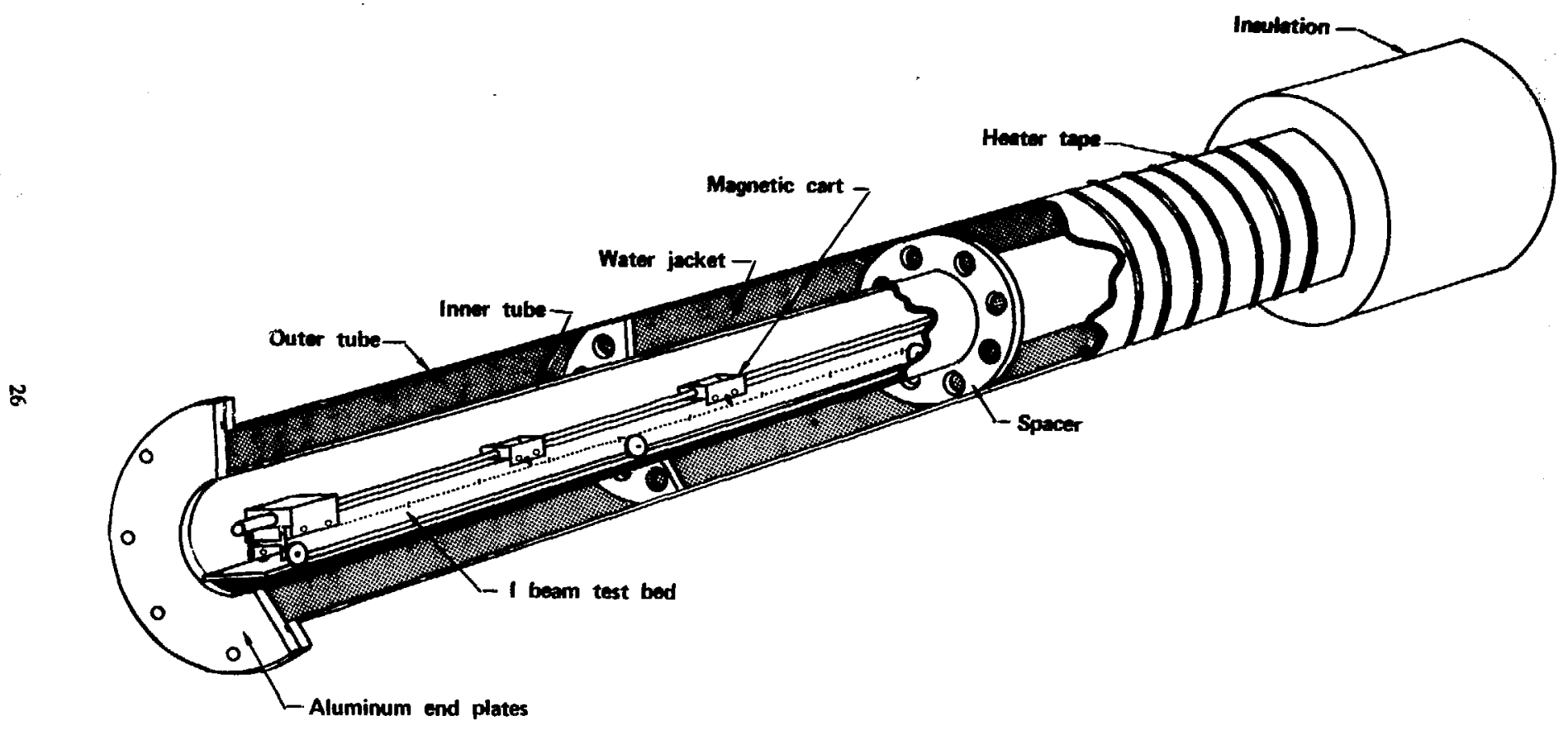

Figure 18. Cutaway drawing of the temperature bath used in temperature-sensitivity studies of the IRAD sonic extensometer. 
The I-beam test fixture was located in the temperature bath at specific temperature, and the sonic probe was inserted into the guide tube. An insulating fonm plug with a small groove to accomodate the thermistor leads and sonic probe cable was then inserted in the end of the tube. Temperature readings were then taken for the four intervals between the magnetic anchors. The readings taken at $20^{\circ} \mathrm{C}$ were used as reference values for subsequent readings at $25,30,35,40,45$, and $50^{\circ} \mathrm{C}$. The probe was removed after readings at a specific temperature and, therefore, was not in place during the relatively long intervals necessary to establish equilibrium associated with increments and decrements in tempeiature. At the peak temperature of $50^{\circ} \mathrm{C}$, a second set of readings was taken and the above process reversed. Finally, a third set of readings similar to the first run was taken as a check of the repeatability of the system.

\subsubsection{Experimental Resulto}

Before any temperature runs, the I-beam test fixture (with magnetic anchors and thermistors located at the five quadrature positions) was placed inside the temperature bath. Over the cotrse of the nearly two months that it took to complete the temperature tests, none of the above system components were moved from their original positions. Since the bath initially was at approximately amblent temperature $\left(24^{\circ} \mathrm{C}\right)$, it was necessary to lower the temperature before taking the first readings. This was accomplished by circulating ice water through the water reservoir until the temperature was well below $20^{\circ} \mathrm{C}$. At this time there was a $0.5^{\circ} \mathrm{C}$ difference between the first and fifth thermistors, corresponding to the water inlet and outlet. The temperature was allowed to increase slowly until it reached $20^{\circ} \mathrm{C}$ and was uniform to within $0.1^{\circ} \mathrm{C}$ along the I-beam. The sonic probe was inserted and a series of readings taken. Then the probe was removed, and the loop controller was set to increase current flow in the heat tape and raise the temperature $5^{\circ} \mathrm{C}$. The above sequence was repeated until probe readings had been obtained at $5^{\circ} \mathrm{C}$ intervals over the range of 20 to $50^{\circ} \mathrm{C}$. At the temperature of $50^{\circ} \mathrm{C}$, a second set of readings was taken, and the above process was reversed. Finally, a third set of readings, similar to the first run, was taken as a check on the repeatability of the system. At each temperature and for each run, the readings were averaged. The results of differences between the sonic-probe reading and the readings obtained at $20^{\circ} \mathrm{C}$ for the first and third runs are plotted in Figs. 19 through 22 for the four intervals and at the specific temperatures cited earlier. The solid circles are for the first run and crosses for the third run. A discussion of the second run will be deferred to later.

As the temperature increases, the 6061-T6 aluminum I-beam undergoes thermal expansion. The coefficient for thermal expansion, which has been well documented, ${ }^{15,16}$ increases linearly with temperature over the temperature range of 20 to $50^{\circ} \mathrm{C}$; it is shown in Fig. 23. Fig. 23 also shows values for the coefficients of thermal expansion used at each temperature to calculate the length changes that occurred for the four intervals between the magnetic anchors as the temperature increased from $20^{\circ} \mathrm{C}$. The resulting change in length of the I-beam as a function of temperature for each irterval is shown as a solid line in Figs. 19 through 22. When the appropriate values for thermal expansion of the I-beam are subtracted from the corresponding probe readings, we obtain the corrected data points. The increase in magnitude of corrected data points with increasing temperature indicates that a definite temperature dependence exists for the sonic probe. We believe the increase in sonic readings with increasing temperature results from a decrease in the sonic velocity in the nickel-cadmium alloy used in construction of the probe.

To determine the correction factor for this temperature dependence, we first obtained a least-squares fit to the corrected data points for each of the four intervals. The results of that effort are shown by the broken lines in each of Figs. 19 through 22; the residual values or the difference between the least squares fit and individual corrected data points are also plotted. The net results suggests that, if the appropriate temperature correction is applied to each interval, the final values do not deviate by more than the \pm 0.002 -in. $(0.051-\mathrm{mm})$ accuracy for the sonic probe readings that was orginally determined in the displacement tests.

To determine the constancy of the temperature correction, we normalized the results by dividing the slope of the least squares fit by the length for each interval. These values are plotted in Fig. 24 as a function of distance along the probe. Each of the four values shown indicate the interval from which they were obtained. A length-weighted average value of $4.05 \times 10^{-6}$ in./in. ${ }^{\circ} \mathrm{C}$ is shown plotted as a broken line for the total segment of the sonic probe used in this test. This value is well within the range of 3.6 to $5.4 \times 10^{-6}$ in./in. ${ }^{\circ} \mathrm{C}$ cited ${ }^{17}$ as representative of the range of correction factors for different sonic probes that are marketed. The variation in the temperature-correction factor is attributed to differences in heat treatment and alloy composition of the material used in fabricating the sonic probes. ${ }^{17}$ Although the 


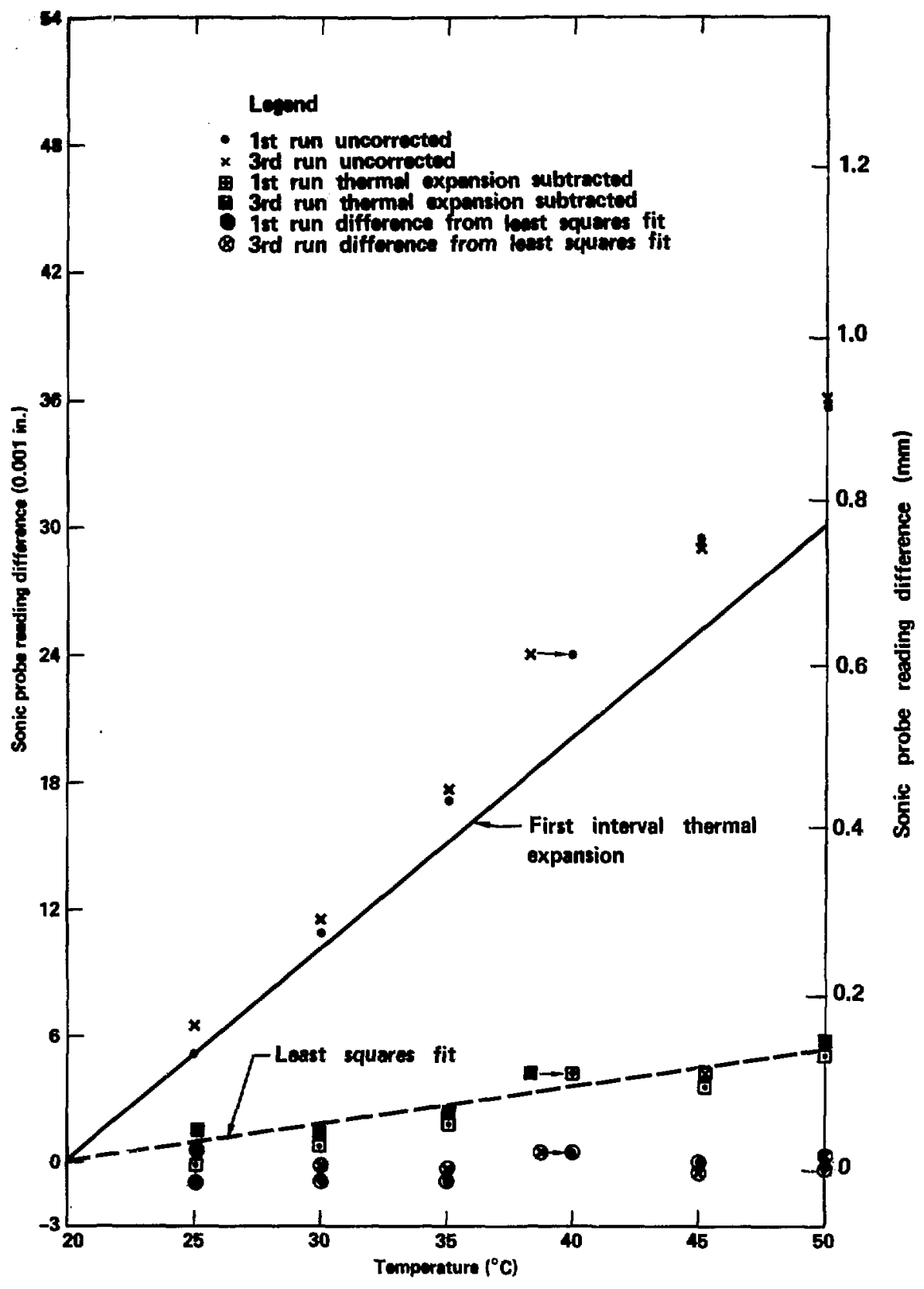

Figure 19. Differences in eonic-probe readings versus temperature for the first interval and first $(\bullet)$ and third $(x)$ temperature runs. 


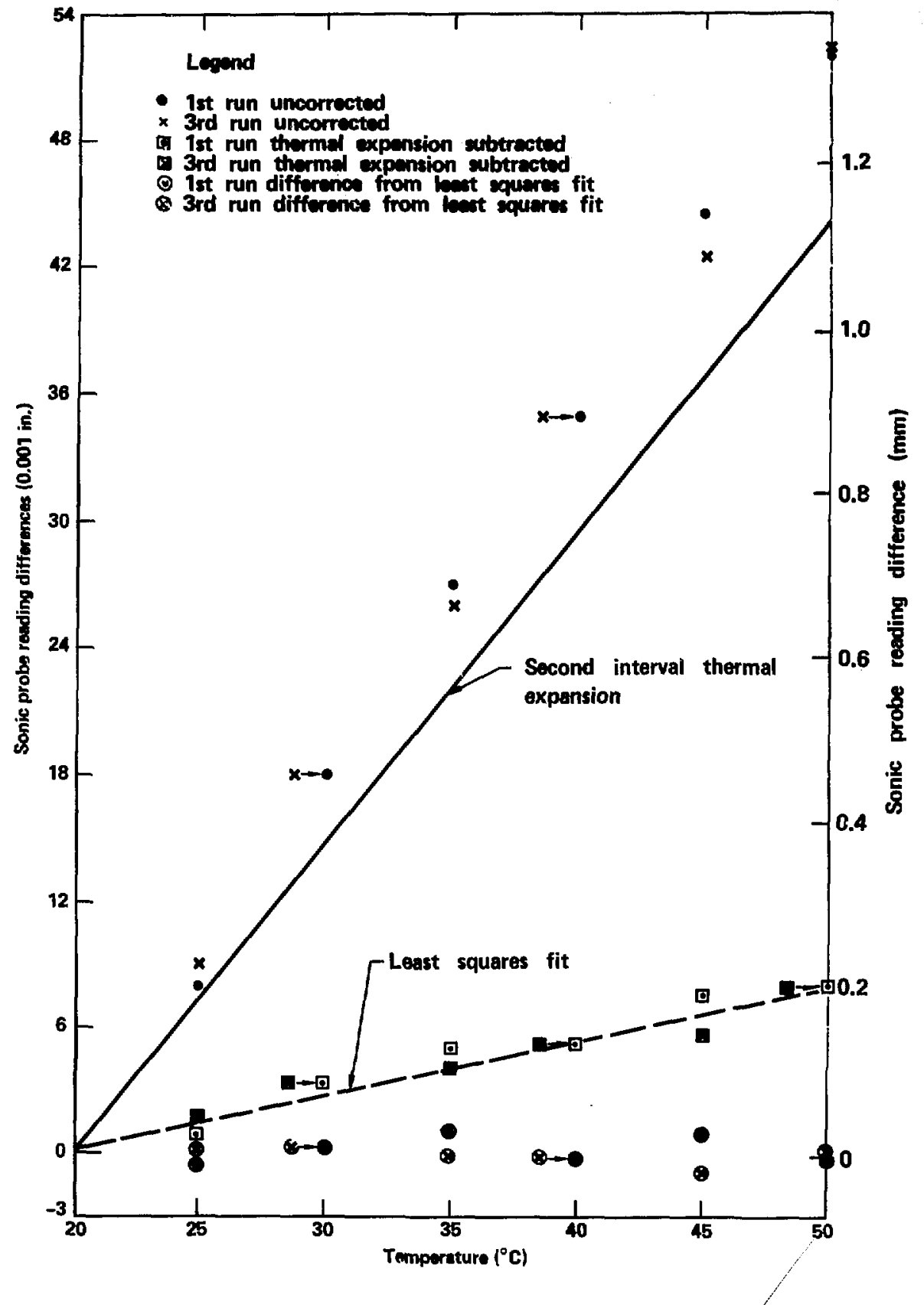

Figure 20. Differences in sonic-probe readinge versus temperature for the second interval and firct $(\bullet)$ and third $(x)$ temperature runs. 


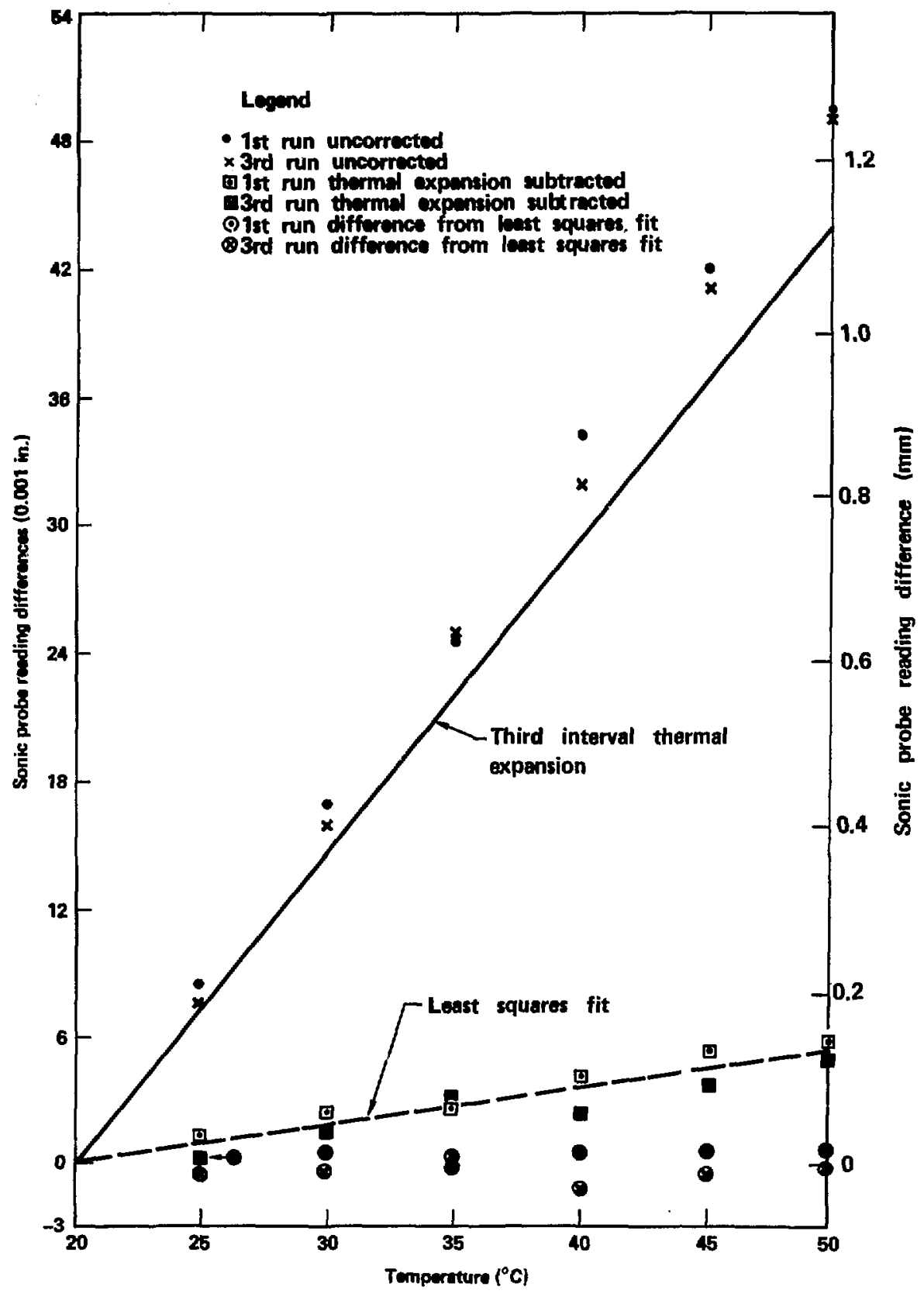

Figure 21. Differences in sonic-probe readinge versus temperature for the third interval and first $(-)$ and third $(x)$ temperature runs. 


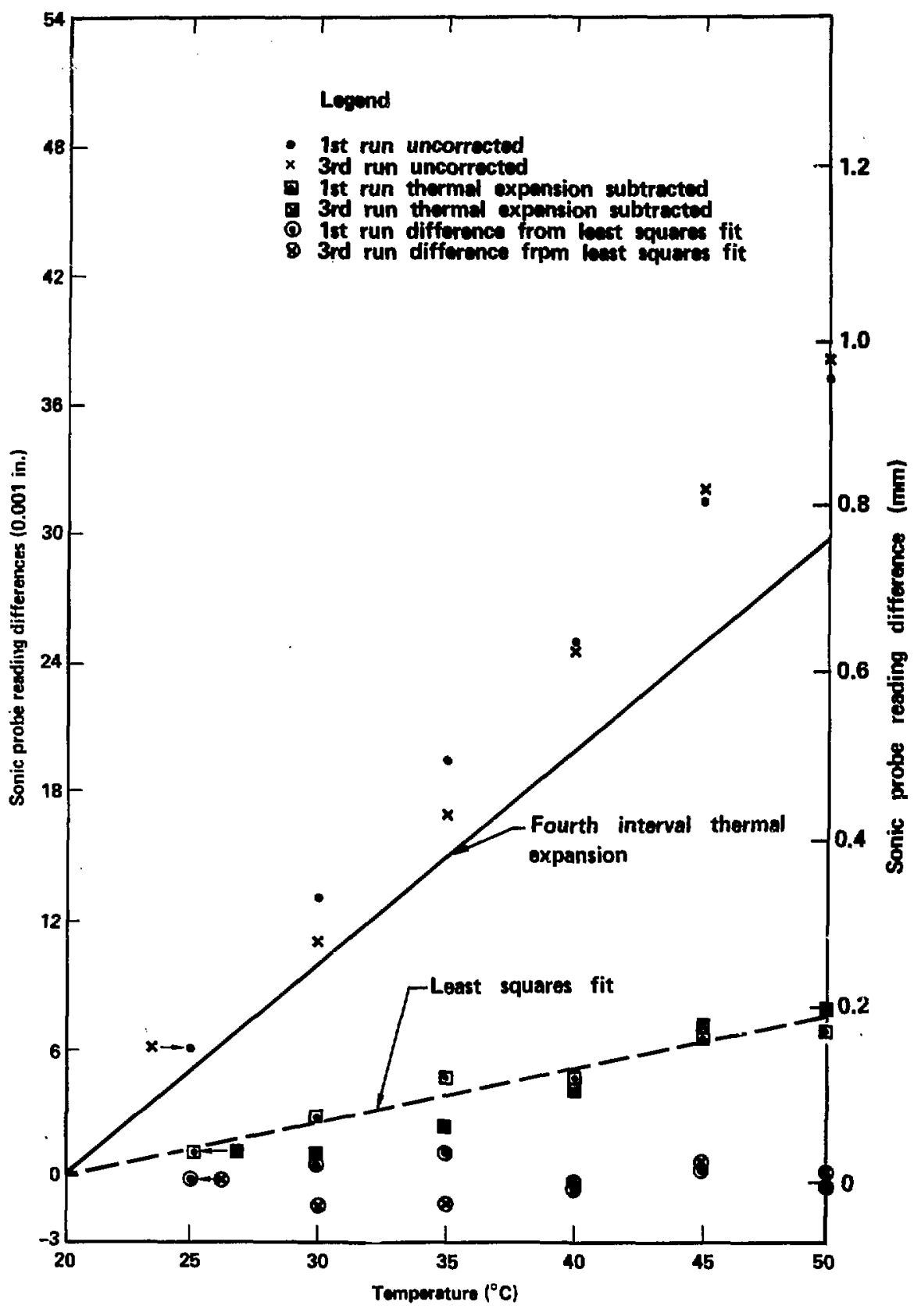

Figure 22. Differences in sonic-probe readings versus temperature for the fourth interval and firet $(\bullet)$ and third $(x)$ temperature runs. 


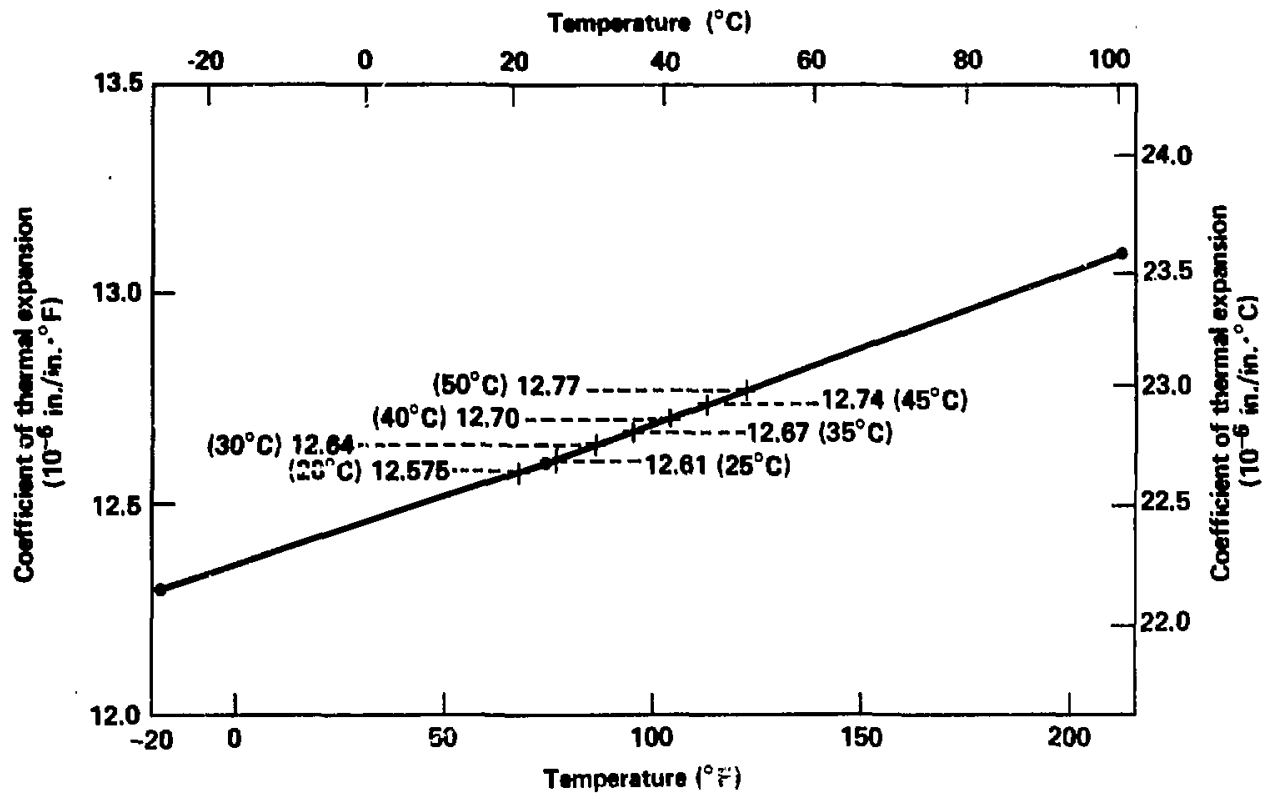

Figure 23. Coefficient of thermal expansion versus temperature for the 6061-T6 aluminum I-beam.

length-weighted average value falls within the manufacturer's general experience, the corrections in the third and fourth intervals deviate markedly from the average. Since only one sonic probe (S/N 1001) was tested, it is presumptuous to make generalized statements regarding their temperature sensitivity. If the variations exhibited in these tests are of concern to a particular user, then a comparable study may be warranted. To obtain better definition of the correction factor with distance along the sonic probe, a larger number of quadrature points for the magnetic-anchor locations would need to be studied.

Earlier, we mentioned a second temperature run that was initiated at $50^{\circ} \mathrm{C}$ and lowered in $5^{\circ} \mathrm{C}$ steps until $20^{\circ} \mathrm{C}$ was reached. Generally, the sonic probe readings at the different temperature values did not agree quite as well with the readings for the first and third runs as they agreed with each other. We hypothesized that this was caused by a small hysteresis in the thermal expansion and contraction of the Ibeam test fixture.

After the prube readings at $50^{\circ} \mathrm{C}$, at the end of the third run, the probe was left in the temperature bath for nearly a full day while the bath was maintained at $50^{\circ} \mathrm{C}$. Then a series of sonic-probe readings were taken at the temperature of $50^{\circ} \mathrm{C}$. The reading changes were within the $\pm 0.002-\mathrm{in} .(0.051-\mathrm{mm})$ error range determined in the displacemient-accuracy phase of this evaluation.

\section{Conclusions and Recommendations}

Evaluation of the electronic circuitry was confined to examination of the MB-7D readout box. An attempt to examine the preamplifier in the probe head was frustrated because signal levels were too low to monitor witiout significantly altering the waveforms. In the MB-7D readout box the accuracy of the crystal oscillator and counter circuit was essentially limited by the inherent accuracy of \pm 0.001 in. $(0.0254 \mathrm{~mm})$ for a binary-coded decimal $(B C D)$ counter. The crystal oscillator appeared to be very stabie and capable of greater accuracy. An external-pulse generator was used to simulate first the drive pulse and 


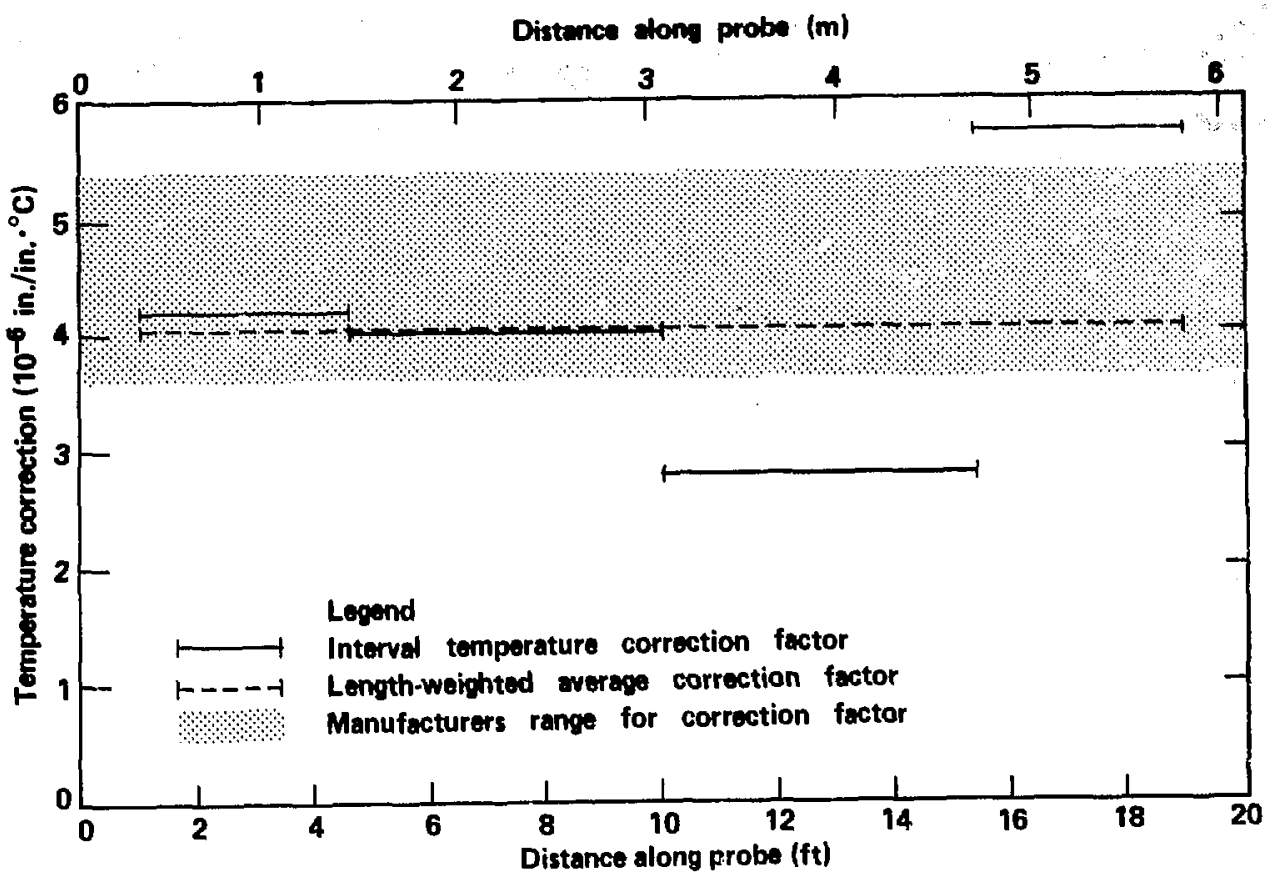

Figure 24. Temperature correction factors (solid line segments) for the four intervals between magnetic anchors versus distance along the probe. The graph also shows the length-weighted-average correction factor (broken line) for the four intervals.

then the return pulse. For drive pulses with amplitudes $\geq 1.4 \mathrm{~V}$, the MB-7D provided reliable readings with both probes for magnetic-anchor separations of 1 and $18 \mathrm{ft}(0.31$ and $5.49 \mathrm{~m})$. The MB-7D readings and the waveforms for the return signals demonstrated excellent insensitivity to variations in the shape of the drive pulse. The external pulse generator was then used to simulate a return signal directly into the MB7D amplifier. Following amplification, this signal activates the Schmitt-trigger circuit that starts and stops the MB-TD display via the counter circuit. Variation of the pulse shape indicated that an input amplitude of $\geq 190 \mathrm{mV}$ was needed to ensure a trigger for the Schmitt circuit. In reality, the counter circuit is sensitive only to the leading edge of the output pulse from the Schmitt-trigger circuit. Results indicated that the rise time for the output of the Schmitt trigger was insensitive to a wide ringe of wave shapes for the return signal that enters the $\mathrm{MB}-7 \mathrm{D}$ readout box.

Finally, the return signals from five magnetic anchors located along the track were compared for the two probes using the $\mathrm{MB}-\mathrm{TD}$ drive pulse. The selected probe (S/N 1001) went through a selection or screening process before being shipped, while the stock probe (S/N A1012RP) was an off-the-shelf item. The five return signals for the selected probe exceeded $500 \mathrm{mV}$ and were uniform in amplitude. For the stock probe, the five return signals were less than $400 \mathrm{mV}$ at the first anchor and steadily decreased in amplitude with distance from the probe head. This difference may be due to quality of probe fabrication or the materials used in that fabrication. This suggests that the return signal for the stock probe may be less than the $190-\mathrm{mV}$ threshold at distances greater than $18 \mathrm{ft}(5.49 \mathrm{~m})$.

We conclude from these studies that the accuracy of the MB-7D readings is primarily controlled by the sonic probe. An accuracy of $\pm 0.001 \mathrm{in}$. $(0.0254 \mathrm{~mm})$ is possible with the MB-7D electronics, and we attribute this variation to the inherent limitations of the BCD-counter circuit. Increasing the accuracy of the $B C D$ counter would require an order of magnitude increase in crystal frequency. This modification 
es not appear practical, but it was not invertigated in detail. The MB-7D readout seems to be a basically well-designed system. We originally felt that redesigning the magnetic anchor might improve tife accuracy of the readings. However, the readings appear to be insensitive to changes in the shape of the return signal. Consequently, modifying the magnetic-anchor design does not appear promising as a method of increasing the accuracy of the MB-TD readings.

The experimental procedure used to evaluate these IRAD sonic extensometers provided a good quantitative estimate of accuracy. Experiments with the test bed indicated that the MB-7D readings for distance between two magnetic anchors were consistently low by about $2 \%$. This error might be eliminated by either modifying the metallurgical composition (decreasing the sonic velocity) of the sonic probe or slightly decreasing the frequency of the crystal oscillator. Whether these modifications are fe asible has not been determined. Since the error is systematic, it can be adequately compensated for without making such modifications. By locating the magnetic anchors at the appropriate quadrature positions and using the micrometers to make small displacenients, it is possible to make the following assessment about the accuracy of the MB-7D readings for both sonic probes. The MB-7D generally records a displaciment that was equal to or less than the actual change in the micrometer setting. Variability of the readings increases with distance from the probe head. Finally, for displacements $\leq 0.05 \mathrm{in}$. (1.27 $\mathrm{mm}$ ), the MB-7D reading error is equal to or less than $\pm 0.002 \mathrm{in} .(0.051 \mathrm{~mm})$ for the selected probe and $\pm 0.003 \mathrm{in} .(0.076 \mathrm{~mm}$; for the stock probe.

A high-explosive test series was conducted in the tunnel complex in the Climax granite forination at NTS to examine the vulnerability of the IRAD sonic-probe system to strong shock waver. is ?2-ft (6.71-m) long, 1.5-in.-diam (38-mm) borehole in the granite was instrumented with five magnetic anchors. Three $50,000 \mathrm{~g}$ accelerometers were installed in close proximity to the borehole to monitor the radial shocks from line charges located $8,4,2$, and $1 \mathrm{ft}(2.44,1.22,0.61$, and $0.31 \mathrm{~m})$ from the borehole containing the magnetic anchors. Results for peak accelerations from the first three line-charge detonations varied between $\simeq 2,100 \mathrm{~g}$ for the $8-\mathrm{ft}(2.44-\mathrm{m})$ test to $\simeq 32,000 \mathrm{~g}$ for the 2 -ft $(0.61-\mathrm{m})$ test. After the 8 -ft $(2.44-\mathrm{m})$ line-charge test, a hexagonal array of HE charges, located in the side drift, was shot to examine sensitivity of the IRAD system to axial-shock propagation along the borehole containing the magnetic anchors. The two gages oriented to measure acceleration for the hexagonal-array (axial-shock) test had too low a signal-to-noise ratio for reliable data reduction.

Preshot and postshot measurements with the IRAD sonic probe indicated relatively minor changes in the readings for the first three line-charge tests and the hexagonal array test. The largest change $(0.015$ to $0.016 \mathrm{in}$. [0.381 to $0.406 \mathrm{~mm}])$ occurred between the last two magnetic anchors for the line-charge radially located $2 \mathrm{ft}(0.61 \mathrm{~m})$ from the anchors. We believe this difference is due to dilation of the rock mass or microcracks induced by the shock wave.

The shock wave from the line charge radially located $1 \mathrm{ft}(0.31 \mathrm{~m})$ from the anchors induced failure of all three radial accelerometers. Postshot inspection of the borehole indicated closure of the magneticanchor borehole at a depth of $\sim 7.5 \mathrm{ft}(2.29 \mathrm{~m})$ from the tunnel wall. There were no fragments or other evidence of the two magnetic anchors that were stationed between the closure and tunnel wall. We conjecture that the shock wave pulverized both anchors and that their debris was expelled by extruded air from the borehole when its back $14.5 \mathrm{ft}(4.42 \mathrm{~m})$ closed. Spall from this shot exposed the line-charge cavity for the $2-\mathrm{ft}(0.61-\mathrm{m})$ shot to a depth of $2.25 \mathrm{ft}(0.69 \mathrm{~m})$. Cavity diameter at that depth varied between $82.6 \mathrm{~mm}$ and $89.0 \mathrm{~mm}$, which agrees well with preshot finite-difference calculations.

These experimental results indicate that the IRAD system has an excellent ability to survive strong shocks. Theese tests were probably more severe than would likely be encountered in typical field operations. The magnetic anchors not only appear to survive, but they also appear to experience very little physical displacement. However, on the basis of the shift noted in the fourth interval on the $2-\mathrm{ft}(0.61-\mathrm{m})$ line-charge shot, we recommend that the magnetic anchors not be subjected to accelerations in excess of $10,000 \mathrm{~g}$. This recommendation is made more in the interest of avoiding damage to the borehole than possible damage to the magnetic anchors. One cautionary remark is necessary: we did not test the system to very strong, purely axial, HE-shock loading. Further investigation to possible vulnerability in this direction might be warranted.

The temperature-sensitivity tests indicated that an increase in the sonic-probe readings occurs with increasing temperature. We attribute this result to a decrease in the probe's sonic velocity with an increase in temperature. Correction factors for this temperature dependence wiere obtained for four different segments of the probe and correction factors for the last two segmerits varied considerably. Although a 
linearly weighted average of $4.05 \times 10^{-6} \mathrm{in} . / \mathrm{in} .{ }^{\circ} \mathrm{C}$ for those four segments was well within the bonds of 3.6 to $5.4 \times 10^{-6}$ in./in. ${ }^{\circ} \mathrm{C}$ cited by the manufacturer, the correction factors for the last two agments were outside those limits. Since only orie sonic probe was involved in these temperature the realts are meant primarily to identify the types of problems that may exist for a prospective user. The seriousness of these problems depends upon the temperature to which the probe may be exposed and the accuracy requirements of the user.

On the basis of our analysis, we recommend the following measures for selecting a probe of acceptable quality and for increasing the accuracy and performance of the IRAD sonic extensometer:

- Carefully screen the sonic probes before making a selection. Prescreening should provide a sonic probe with an accuracy of $\pm 0.002 \mathrm{in} .( \pm 0.051 \mathrm{~mm})$ for its total length. In addition, the return signals from the farthest interval should substantially exceed the trigger threshold. This would require the cooperation of the manufacturer and might increase costs.

- Investigate the possibility of establiohing additional quality controls in the manufacturing of the sonic probes. An altemative approach would be to establish practical specifications that would sitisfy the user's requirements,

- Establish a test-bed facility at the user's site, similar to the one used at LLNL to perform the accuracy and temperature-dependence tests reported here, to fully document the characteristics of each probe before use.

- Incorporate a microprocessor into the MB-7D that would provide one reading that is an arithmetic (objective) average of all the readings. This would eliminate the subjectivity inherent in inentally averaged readings, but it would have the disadvantage of not giving the range over which the readings vary. Perhaps a microprocessor could be provided as a field-selectable cption to the present method.

- Adopt a standard method for interpreting the readout data. An example may be to take three successive readings and average the results.

The present study addressed certain basic areas of performance of the IRAD sonic extensometer. Additional study is required to examine the sonic extensometer's performance in other respects:

- The temperature sensitivity of the extensometer must be investigated further if it is to be used to acquire very precise data at elevated temperatures. This test requirement is dictated by the accuracy of the prospective user and the environment to which the probe may be exposed. The systems and procedures used in the present study might be adopted for such tests.

- The anchorage system's response to axial shock generated by nearby explosions should be examined. Such a test should be conducted on a much larger scale than was feasible in the present study, e.g., the bench blasting used to mine the central drift at the Climax facility.

- The MB-TD readout box should be modified to allow the option of remote reading if the extensometer is to be part of an automated data-acquisition network.

- The probe and probe head should be thoroughly evaluated to determine if they could be made more accurate.

\section{Acknowledgments}

This research was completed as part of a joint U.S./Canadian cooperative agreement on nuclear waste management. The contract was administered through the Department of Energy's Office of Crystalline Repository Development at the Battelle Memorial Institute. It was funded as part of DOE's Crystalline Repository Project.

The authors extend their appreciation to: W. F. Ubbes of DOE-Office of Crystalline Repository Development for his interest and support of this work; T. C. z.ven, B. O. Sellick, Jr., and W. C. Schnoor for fabricating the test bed; R. Ruiz and J. J. Scarafiotti for construction and electronics support of the temperature reservoir and assistance in the high explosive tests; and T. H. Hoheisel for calibrating the thermistors. The authors are especially indebted to T. F. Stubbs and G. W. Smith of EG\&G for reducing data from the high-explosives tests. The authors thank Dr. P. W. Runstadler, Jr., of IRAD Gage for providing information about the electronic circuitry. The authors aiso thank Dr. E. N. Lindner of OCRD, and L. D. Ramspott, F. E. Heuze, and G.A. Metzger for their critical reviews of this report. 


\section{References}

1. L. D. Ramspott, L. B. Ballou, R. C. Carlson, D. N. Montan, T. R. Butkovich, J. E. Duncan, W. C. Patrick, D. G. Wilder, W. G. Brough, and M. C. Mayr, Technical Concept for a Test of Geological Storage of Spent Reactor Fuel in the Climax Granite, Nevada Test Site, Lawrence Livermore National Laboratory, Livermore, CA, UCRL-52796 (1979).

2. W. G. Brough and W. C. Patrick, Instrumentation Report No. 1; Specification, Design, Calibration, and Installation of Instrumentation for an Experimental, High-Level Nuclear Waste Facility, Lawrence Livermore National Laboratory, Livermore, CA, UCRL-53248 (1981).

3. F. E. Heuze, T. R. Butkovich, and J. C. Peterson, An Analysis of the "Mine-By" Experiment, Climax Granite, Nevada Test Site, Lawrence Livermore National Laboratory, Livermore, CA, UCRL-53133 (1981).

4. T. R. Butkovich, J. L. Yow, Jr, and D. N. Montan, "Influence of Heat Flow and Drift Clusure During Climax Granite Spent Fuel Test: Measurement and Calculations," Proceedings of th: International Conference on Radioactive Waste Management, Winnipeg, Manitoba, Canada, September 12-15, 1982.

5. W. C. Patrick, R. C. Carlson, and N. L. Rector, Instrumentation Report No. 2; Identificalisn, Evaluation, and Remedial Actions Related to Transducer Failure at the Spent Fuel Test-Climax, Lawrence Livermore National Laboratory, Livermore, CA, UCRL-53251 (1981).

6. D. G. Wilder, F. Rogue, W. R. Beloff, E. Binnall, and E. C. Gregory, Executive Committee ReportGeotechnical Instrumentation Working Group Meeting, Lawrence Livermore National Laboratory, Livermore, CA, UCRL-87183 (1982).

7. I. Hawkes, Measurement of Mine Roof Movement, U.S. Department of the Interior, Bureau of Mines Technical Report, 78-1, Contract No. H0366033 (1978).

8. W. C. Patrick and G. A. Metzger, Preliminary Evaluation of IRAD Sonic Extensometers for Application in the Canadian Underground Research Laboratory, Letter Report to G. R. Simmons, Nuclear Fuel Waste Management, Whiteshell Nuclear Research Establishment, Atomic Energy of Canada Limited, Pinawa, Manitoba, ROEILO, Canada (1982).

9. R. Tenenbaum, MB-7 Theory of Operation, IRAD Gage, Lebanon, NH, Technical Memo 82-2 (1982).

10. P. W. Runstadler, Jr., IRAD Gage, private communication (1983); see also H. D. Glenn and L. S. Butler, Evaluation of the IRAD Sonic Extensometer for Application in the Canadian Underground Research Laboratory (FY 1983), Lawrence Livermore National Laboratory, Livermore, CA, UCID-19982 (1983).

11. A. N. Lowan, N. Davids, and A. Levenson, "Table of the Zeros of the Legendre Polynomials of Order 1-16 and the Weight Coefficients for Gauss' Mechanical Quadratare Formula," Bulletin of th.' American Mathematical Society, 48, 10 (1942).

12. W. C. Patrick and W. G. Erough, Response of Borehole Extensometers to Explosively Generated Dynamic Loads," Lawrence Livermore National Laboratory, Livermore, CA, UCRL-53087 (1980).

13. T. R. Butkovich, Lawrence Livermore National Laboratory, Livermore, CA, private communication (1984).

14. J. F. Sciicic2, SOC73, A One-Dimensional Wave Propagation Code for Rock Media, Lawrence Livermore National Laboratory, Livermore, CA, UCRL-51689 (1974).

15. E. B. Kaikinger (Editor), Lawrence Livermore National Laboratory Engineering Standard Reference FSC 95-Metals (1980).

16. Structural Alloys Handbook, vol. 2, Mechanical Properties Data Center, Batelle Memorial Institute, Colunibus, $\mathrm{OH}(1984)$.

17. J. Tellerman, Temposonics, Plainview, N.Y., private communications (1984). 